\title{
Población, política sanitaria e higiene pública en la España del siglo XVIII ${ }^{1}$
}

\author{
Gerard Jori ${ }^{2}$
}

\begin{abstract}
RESUMEN
La actitud favorable del pensamiento ilustrado hacia las poblaciones numerosas, basada en la creencia de que cuanto más poblado sea un país mayor será su capacidad para obtener riquezas y poder, coadyuvó decisivamente a que durante el siglo XVIII la salud y la enfermedad comenzaran a ser conceptualizadas como problemas políticos y económicos que demandaban una gestión pública. Los tratadistas de la policía médica formularon numerosas propuestas para elevar el nivel de salud de las poblaciones, defendiendo que la ejecución de tales medidas correspondía al poder político. Este, a su vez, fue irrogándose una misión de policía sanitaria que, con sus reglas generales de higiene, hizo de los espacios urbanos auténticos objetos de medicalización, anticipando, al menos esquemáticamente, algunos principios generales de la planificación urbanística del siglo XIX. El presente trabajo constituye una aproximación a la forma en que se desarrolló este proceso en la España del siglo XVIII.
\end{abstract}

Palabras clave: Mercantilismo, siglo XVIII, policía médica, higiene pública, Barcelona.

\begin{abstract}
One of the most characteristic features of European mercantilist thought is the favorable attitude of this economic doctrine toward large populations, based on the belief that as more populous a country is, greater is its ability to obtain wealth and power. That is the reason why during the eighteenth century health and disease began to be conceptualized as political and economic problems, and required a collective administration. Writers of medical police dealt with different proposals to raise the level of population health, arguing that the implementation of these measures belonged to the political power. This power, in turn, assumed a sanitary function, and through general hygienic rules turned urban spaces in objects of medicalization, anticipating, at least schematically, some general principles of urban planning. This work is an approximation of how this process was developed in eighteenth-century Spain.
\end{abstract}

Key words: Mercantilism, $18^{\text {th }}$ century, medical police, public hygiene, Barcelona.

1 Este trabajo ha sido financiado por el Programa Nacional de Formación del Profesorado Universitario (FPU) del Ministerio de Ciencia e Innovación de España. También ha contado con fondos procedentes del proyecto de investigación CSO-201021076-C02-01, titulado "El control del espacio y los espacios de control. Territorio, ciudad y arquitectura en el diseño y las prácticas de regulación social en la España de los siglos XVII al XIX" y financiado por el mismo Ministerio. Artículo recibido el 19 de enero del 2012, aceptado el 18 de mayo de 2012 y corregido el 16 de junio de 2012.

2 Departamento de Geografía Humana, Universidad de Barcelona (España). E-mail: gerardjori@ub.edu 
A fines del siglo XVIII, el político francés Nicolas Bergasse habló de la posición políticamente privilegiada que habían alcanzado los médicos de su tiempo: "los médicos conforman una corporación política cuyo destino está vinculado al del Estado y cuya existencia resulta esencial para la prosperidad del mismo" (Bergasse, 1781: 67). Con estas palabras Bergasse no hizo otra cosa que resumir el advenimiento de la llamada biopolítica, concepto acuñado por Michel Foucault para designar la forma en que, a partir del siglo XVIII, se han intentado racionalizar los problemas que plantea a la práctica gubernamental el ejercicio del poder, no ya sobre un territorio, sino sobre un conjunto de seres vivos organizados como población (Foucault, 1999a: 209). Esta forma de control social no se operó solamente a través de la conciencia y la ideología, sino que se ejerció sobre el cuerpo humano constituido en realidad biopolítica, con lo cual fenómenos como la salud, la natalidad o la longevidad pasaron a ser considerados como objetos de preocupación política. Ello explica por qué en el transcurso del setecientos la actividad médica dejó de ser esencialmente clínica para comenzar a adquirir una marcada dimensión social. En tanto que técnica general de salud, y no ya como arte dedicado a la curación individual de las enfermedades, la medicina fue ocupando un lugar cada vez más destacado en el interior de las estructuras político-administrativas, al tiempo que los médicos se fueron asentando en las diferentes instancias del poder, o al menos se fueron dedicando cada vez más a actividades públicas con el objetivo de mantener al cuerpo social en un estado permanente de salud.

Para Foucault (1999b), la génesis de la medicina social se encuentra en la sucesión y confluencia de tres fenómenos estrechamente vinculados al origen del capitalismo: el desarrollo del Estado, la aceleración del proceso de urbanización y la aparición del proletariado industrial. En función del predominio de cada uno de estos fenómenos se diferencian tres formas distintas de medicina social que, a su vez, constituyen otras tantas fases del proceso de configuración de esta: la medicina del Estado, la medicina urbana y la medicina de la fuerza de trabajo. En los tres casos el Estado asumió la función de garantizar la salud de los ciudadanos como un medio para preservar la fuerza física nacional, que alude, básicamente, a la capacidad de producción y al poderío militar; "public health is public wealth", rezaba una extendida máxima británica. Los caracteres biológicos de la población pasaron a ser considerados como elementos clave de la gestión política y económica, siendo necesario organizar en torno a ellos un dispositivo que garantizase su sometimiento y asegurase el incremento constante de su utilidad. Fruto de este empeño es una incipiente tecnología de la población, que acabaría de perfeccionarse en el siglo XIX, y que incluía aspectos tan diversos como las estimaciones demográficas, el cálculo de las tasas de morbidez, el estudio de las influencias recíprocas entre el crecimiento de la riqueza y el de la población, los estímulos al matrimonio y la natalidad, o la mejora de la educación y de la formación profesional.

En un texto de 1976 titulado "La política de la salud en el siglo XVIII", Foucault continuó profundizando en estos temas desarrollando la noción de nosopolítica, cuya conceptualización expresaría, no tanto una intervención uniforme del Estado en la práctica de la medicina, como la toma de conciencia por parte de la sociedad de que la salud y la enfermedad constituyen problemas políticos y económicos que las colectividades deben intentar resolver a través de decisiones globales. Por consiguiente, la nosopolítica que se desarrolló durante el setecientos implica la consideración de la salud como uno de los objetivos básicos del poder político. No se trata de un fenómeno privativo del Siglo de las Luces ya que en épocas anteriores el bienestar físico de los individuos también había sido concebido como un asunto que demandaba una gestión pública. Con todo, durante esa centuria se impusieron nuevas reglas a la nosopolítica y, sobre todo, se dotó a esta categoría de un nivel de análisis explícito y concertado que nunca antes había tenido. Ahora ya no se trata de garantizar un relativo bienestar físico a los sectores más frágiles de la sociedad, como los pobres y desocupados, sino que se persigue elevar el nivel de salud del conjunto del cuerpo social. "El imperativo de salud -nos aclara Foucault- es a la vez un deber para cada uno y un objetivo general" (Foucault, 1999c: 331), que trató de alcanzarse mediante el despliegue de una política sanitaria cuyos dos caracteres esenciales fueron, de un lado, el privilegio de la infancia y 
la medicalización de la familia, y, del otro, el desarrollo de la higiene pública y el funcionamiento de la medicina como instrumento de control social (Foucault, 1999c: 333-338).

Este trabajo constituye una aproximación a la forma en que se desarrolló en la España del siglo XVIII el segundo de los procesos mencionados. No pretendemos abarcar la pluralidad de materias que entraron en liza. Nuestro objetivo es mostrar la existencia de un debate teórico sobre el resguardo de la salud pública que dio lugar a algunas realizaciones importantes. En el primer apartado presentaremos los principales rasgos de dicho debate, que relacionaremos con algunos de los postulados del pensamiento mercantilista europeo. A continuación, estudiaremos la aplicación de los principios teóricos en España, haciendo referencia a las intervenciones promovidas desde las dos instancias básicas del poder político: el gobierno central y las autoridades municipales. Finalmente, examinaremos un informe elaborado en 1781 por la Academia Médico-Práctica de Barcelona, el cual nos permitirá ponderar la trascendencia que tuvieron algunas ideas médicas sobre el origen y la evolución de las enfermedades en el surgimiento de la higiene pública. A modo de conclusión, realizaremos algunas consideraciones sobre el alcance de la geografía histórica e insertaremos nuestro trabajo en los desarrollos teóricos más recientes de esta subdisciplina.

\section{El debate teórico sobre el resguardo de la salud pública. La policía médica y su engarce con el pensamiento mercantilista}

Es innegable que el desarrollo de la sociedad industrial en el siglo XIX comportó la aparición de problemas urbanos que eran cuantitativa y cualitativamente distintos a los del Antiguo Régimen, problemas a los que trató de dar respuesta una nueva disciplina, el urbanismo, que se distinguía de las artes urbanas anteriores por su carácter reflexivo y crítico y por su pretensión de cientificidad. Con todo, no puede sostenerse, como parecen sugerir algunas concepciones rupturistas, que las nuevas formulaciones manaran de la nada, pues en el transcurso del siglo XVIII se había gestado una rica tradición de pensamiento urbano que, en buena medida, sirvió de base a las ideas y realizaciones de los urbanistas del ochocientos.

Dicha tradición quedaba en gran medida englobada dentro de la llamada "ciencia de policía", una parcela del conocimiento que, según un diccionario de la época, se refería al "buen orden que se observa y guarda en las ciudades y repúblicas, cumpliendo las leyes y ordenanzas establecidas para su mejor gobierno" (Diccionario de la lengua castellana compuesto por la Real Academia Española, reducido a un tomo para su más fácil uso, 1780: 735). Lo enmarañado de este objetivo hace que sea difícil precisar cuáles eran las materias que incumbían a la ciencia de policía. Según Nicolas Delamare, autor de uno de los tratados que alcanzaron una mayor difusión, el propósito de esta disciplina residía "en conducir al hombre a la felicidad más perfecta que pueda gozar en esta vida", lo que dependía del disfrute de tres tipos de bienes: los del alma, los del cuerpo y los de la fortuna (Delamare, 1705: s/p). Por consiguiente, a la ciencia de policía le correspondía mantener y promover los valores asociados a esa trilogía, lo que se traducía en el tratamiento de una gran diversidad de materias que Delamare agrupó en once rúbricas, las cuales habían de constituir las distintas temáticas sobre las que debía versar cada uno de los libros de su tratado: religión, costumbres, salud, víveres, vialidad, seguridad, artes y ciencias liberales, comercio, manufacturas, trabajadores y pobreza.

Tal pluralidad de competencias da una idea del carácter generalista que tenía la ciencia de policía, lo que, a la postre, acabaría determinando su desintegración en saberes específicos. Quienes cultivaron este ámbito del conocimiento no solo formularon criterios y recomendaciones relativos a la ordenación urbana, sino que se ocuparon del funcionamiento de la ciudad en su conjunto, superponiendo, además, distintos niveles discursivos. De ahí que fuera habitual que en los tratados de policía se combinaran propuestas de índole muy general sobre la observancia religiosa o las buenas costumbres, con otras mucho más concretas y mundanas acerca de la higiene pública o la pavimentación de las 
calles. Otro de los rasgos más característicos de la policía urbana del siglo XVIII fue el carácter práctico, directo y continuo de sus intervenciones. La atención de los tratadistas no se dirigió tanto a las situaciones conflictivas como a la cotidianeidad del ciudadano, pues al intervenir sobre esta esfera perseguían lograr una sociedad más disciplinada, laboriosa y sumisa, anticipando, de este modo, los cambios en las estrategias y mecanismos de control social que se producirían a raíz de las grandes transformaciones políticas iniciadas en las postrimerías del setecientos.

En España, la ciencia de policía no fue objeto de ninguna aproximación sistemática que abordase, de manera metódica, las distintas materias que conformaban esta disciplina. Ello, sin embargo, no quiere decir que los autores españoles no reflexionaran sobre dichos asuntos, pues como han mostrado las investigaciones de Pedro Fraile (1991, 1997, 1998) la producción española en el terreno de la policía urbana fue amplia, variada y, en ocasiones, excepcional. Al margen de algunas obras pioneras escritas durante el Siglo de Oro, se editaron numerosas versiones de tratados extranjeros, que solían publicarse con generosas ampliaciones del traductor. Sin duda, la aportación española original más importante fue debida a Valentín de Foronda, autor de unas "Cartas sobre la policía" publicadas en 1801. El estilo epistolar de la obra es, al mismo tiempo, su mayor fuerza y debilidad, pues aunque permite al autor pasar sin dificultad de un tema a otro, impide que el libro tenga un planteamiento metodológico general que dé coherencia a los contenidos específicos. Asimismo, numerosos autores españoles abordaron en un sinfín de textos diseminados cuestiones que entraban plenamente dentro de las atribuciones de la ciencia de policía, conformando, así, una rica producción dispersa.

Cuando Delamare hablaba de los bienes del cuerpo se refería a todo lo relativo a la vida material de los individuos, incluyendo, dentro de este apartado, lo tocante a la salud pública. En todos los países europeos, aunque de forma especial en los Estados alemanes, los tratadistas de la ciencia de policía fueron prestando una atención creciente a este asunto, siendo así que durante la segunda mitad del siglo XVIII se hizo de uso cada vez más frecuente el concepto de "policía médica", que podemos definir como el conjunto de teorías surgidas de los fundamentos ideológicos del absolutismo y el cameralismo germánicos para ser aplicadas en la esfera de la salud colectiva. En un conocido artículo publicado en 1953, el historiador de la medicina George Rosen argumentó que el origen de la policía médica se encuentra estrechamente vinculado a la actitud del pensamiento mercantilista hacia la sociedad organizada $y$, en particular, a su anhelo de mantener una población en constante aumento, lo que se justificaba por motivos políticos, económicos y militares. Para la doctrina mercantilista el producto total social dependía directamente del volumen de la mano de obra, por lo que, según se argumentaba, el aumento de la población conducía a un incremento del producto bruto anual y, por consiguiente, permitía acrecentar el poder del Estado (Hoselitz, 1953: 14). De ahí la necesidad de crear conscientemente un "capital humano" impulsando planes de instrucción, promoviendo la fecundidad y la inmigración o asegurando la salud de la colectividad.

Las ideas de Johann Heinrich Gottlob von Justi, uno de los principales representantes del cameralismo, equivalente alemán del mercantilismo, ejemplifican muy bien la filosofía que inspiró el desarrollo de la policía médica durante el siglo XVIII. En 1758, este autor dio a conocer un influyente tratado titulado Grundsätze der Polizeywissenschaft, que al cabo de unos años sería traducido al castellano como Elementos generales de policía (1784) por el jurista Antonio Francisco Puig y Gelabert. Una de las secciones del tratado -la segunda del primer libro- está íntegramente dedicada a las políticas poblacionistas, y en ella Justi hizo gala de su admiración por las sociedades numerosas, afirmando que "debe tenerse por regla fundamental que nunca será sobrado el número de habitantes, por más razones que se aleguen para probar lo contrario" (Justi, 1996: 42). La mencionada sección se divide en tres capítulos, cuyos epígrafes son sumamente elocuentes de las intenciones del autor: "Medios que deben emplearse para atraer a los extranjeros", "De los medios de aumentar la población con los mismos nacionales" y "Del cuidado que debe tener el soberano en impedir las enfermedades y la mortandad entre sus súbditos". 
Respecto a esta última cuestión, que es la que más nos interesa en este trabajo, el alemán formuló un buen número de recomendaciones destinadas a elevar el nivel general de salud. En primer lugar, propuso la creación en la capital de cada reino de un Consejo de Sanidad formado por médicos y personas versadas en la policía. Este organismo debería velar por la salud de los ciudadanos adoptando todas las providencias que fueran necesarias para prevenir las enfermedades epidémicas. Asimismo, debería fomentar el cultivo de la medicina y de disciplinas afines como la farmacia, evitando, en todo lo posible, el intrusismo de curanderos y demás charlatanes. El control de la salubridad urbana se delegaría a un Colegio de Medicina que, entre otras actividades, debería "hacer enjugar las lagunas cuyas exhalaciones corrompen el aire, procurar a los habitantes aguas más sanas [...], hacer limpiar la ciudad, impedir el mal aire dando una nueva forma a las casas, a fin de que circule en ellas más libremente" (Justi, 1996: 53). Otro de los ámbitos al que las autoridades políticas debían prestar atención es el de la vigilancia de los artículos comercializados, especialmente de los alimentos, pues, al decir de Justi, "el vino alterado, la mala cerveza, las frutas cogidas antes de su perfecta madurez y las mercaderías gastadas son tan dañosas a la salud, que no se sabe castigar con bastante severidad a los que defraudan y engañan al público con el objeto de un sórdido interés" (Justi, 1996: 53). La preocupación del alemán por el crecimiento de los efectivos demográficos vuelve a aflorar cuando aborda el tema del suicidio, al que consideró un crimen por privar al Estado de su fuerza de trabajo, lo que había de llevar a las autoridades a impedirlo por todos los medios.

Posiblemente, el primer autor en utilizar el término de policía médica fue Wolfgang Thomas Rau, que en 1764 publicó un breve texto titulado Gedanken von dem nutzen und der nothwendigkeit einer medicinischen policey-ordnung in einem Staat, que podemos traducir como Consideraciones sobre la utilidad y la necesidad de un reglamento de policía médica en un Estado. En este opúsculo Rau formuló diferentes propuestas para elevar el nivel de salud de los pueblos -entre las que figuran la mejora de las enseñanzas médicas, la lucha contra el intrusis- mo profesional, la atención a la infancia, el cuidado de las mujeres durante el embarazo y la lactancia o la defensa frente a las enfermedades endémicas y epidémicas-, y postuló que correspondía al Estado la aplicación de tales medidas por medio de reglamentos administrativos. La reflexión acerca del resguardo de la salud pública sería objeto de otras muchas aproximaciones, entre las que resulta de cita obligada el monumental System einer vollständigen medizinischen polizey (Sistema integral de policía médica), obra del médico alemán Johann Peter Frank aparecida en nueve volúmenes -tres de ellos de carácter suplementario y dos publicados póstumamente- entre 1779 y 1827.

La idea según la cual el bienestar físico de las poblaciones resultaba indispensable para la prosperidad del Estado llevó a Frank a proponer este minucioso código sanitario destinado, no ya a los médicos o a la educación popular, sino a los dirigentes de mentalidad reformista que debían velar por la salud y la longevidad de las sociedades que gobernaban. Para alcanzar este objetivo el Estado tenía que regular hasta los más mínimos detalles de la existencia humana, lo que en ocasiones llegaba al paroxismo. Como nos es imposible resumir en unas pocas palabras el System de Frank, bastará con enunciar la estructura general de la obra para dar una idea de la diversidad de aspectos considerados. El primer volumen (1779) está consagrado al matrimonio, la procreación, el embarazo y el parto; el segundo volumen (1780) se ocupa de las relaciones sexuales, la prostitución, las enfermedades venéreas y el aborto, y en él también se abordan distintas cuestiones relacionadas con el cuidado y la educación de los niños; en el tercer volumen (1783) se exponen los temas relacionados con la nutrición, el control alimentario, la vestimenta, la vivienda y las diversiones populares; el cuarto volumen (1788) está dedicado a la seguridad pública, los accidentes, los delitos y las muertes por causas violentas; el quinto volumen (1814) prosigue con los mismos temas y trata algunos aspectos relativos a la muerte; el sexto volumen, aparecido en tres partes entre 1817 y 1819 , presenta un panorama general del arte de curar y su influencia en el bienestar de la sociedad, y plantea los principales problemas de la educación médica; los tres últimos volúmenes, de carácter suplementa- 
rio, abordan temas muy heterogéneos, tales como las estadísticas vitales, la asistencia hospitalaria, la higiene militar o la profilaxis de las enfermedades venéreas.

Como puede comprobarse, el enfoque de Frank es el de un médico que dirige la existencia del hombre desde la cuna hasta la tumba, con el fin de protegerle de las amenazas que proceden de su entorno físico y social. Los individuos, por su parte, han de someterse a tales reglamentaciones, pues solo así obtendrán la vitalidad y el vigor físico que se les demanda. En consecuencia, las elaboraciones teóricas de Frank aparecen revestidas de una pátina autoritaria y paternalista que encajaba muy bien dentro de los planteamientos del despotismo ilustrado, forma de gobierno surgida en la segunda mitad del siglo XVIII que trató de conciliar el absolutismo con las ideas filosóficas de la Ilustración, y que intentó conjugar los intereses de la monarquía con el bienestar de los gobernados. Pero al mismo tiempo las formulaciones del médico alemán representaban una clara ruptura con los supuestos de la política sanitaria que había sido operativa durante todo el Antiguo Régimen, pues esta se había concentrado, casi con exclusividad, en dos únicos aspectos: la defensa antiepidémica y la asistencia benéfica de los enfermos pobres. De ahí que Frank pueda ser considerado como uno de los padres de la medicina social.

El tratado de Frank tuvo una influencia extraordinaria y condicionó el desarrollo posterior de la higiene pública en toda Europa. La primera obra sobre policía médica impresa en España se debió al catalán Vicente Mitjavila, y fue publicada en 1803 en el Suplemento al Semestre Médico Clínico, una de las primeras revistas españolas de medicina. El autor participaba de las tendencias generales en este tipo de reflexión. Afirmó que "las ventajas y prosperidad de una población están en razón directa de la robustez y sanidad de sus moradores" (Mitjavila y Fisonell, 1803: 69), lo que le llevó a sostener que la profesión médica debía contribuir a elevar los niveles generales de salud proponiendo normas que regulasen asuntos tan diversos como la localización de hospitales y cárceles, el control de la alimentación o la organización de las escuelas públicas.
Mayor interés revisten las consideraciones efectuadas por Valentín de Foronda en sus Cartas sobre la policía (1801), que pese a no constituir una obra específica sobre policía médica contienen algunas de las aportaciones originales españolas más destacadas a este ámbito del saber. En concreto, la Carta II, fechada en 1793 y dirigida, como todas las demás, a Pedro Cevallos, a la sazón Primer Secretario de Estado, está íntegramente dedicada a esa materia. En dicho texto Foronda sentó el principio de que la agenda de actividades gubernamentales tenía que considerar el resguardo de la salud colectiva, pues, en su opinión, "los soberanos no deben tener otra diversión que el dulce y delicioso estudio de hacer felices a sus vasallos; y como estos no pueden serlo sino disfrutando de una salud robusta, será una obligación de Vmd. cuidar de este importante objeto" (Foronda, 1801: 11). A continuación, el autor detalló una serie de recomendaciones para asegurar la salud de las poblaciones. Un buen número de ellas están referidas a la pureza del aire atmosféri$\mathrm{co}$, siendo de destacar que, a las providencias ya clásicas sobre la limpieza de las calles, la instalación de letrinas o la ubicación de los cementerios, Foronda agregó un conjunto de medidas destinadas a alterar la composición química del aire en el interior de los hospitales y otros lugares cerrados, demostrando estar al corriente de los recientes descubrimientos en el campo de la identificación de los gases atmosféricos.

El segundo gran tema abordado por Foronda es el del control alimentario. El autor propuso diversas medidas para garantizar la potabilidad del agua, así como para evitar la adulteración de alimentos básicos como el pan, la carne o el vino. En tercer lugar, el alavés habló de los medios para prevenir determinadas enfermedades. Por ejemplo, propuso que se castigase severamente a las prostitutas afectadas por la sífilis, pues las consideró "unas asesinas, no solo de una persona, sino de generaciones enteras" (Foronda, 1801: 30). Pero al mismo tiempo, considerando que el "objeto de las leyes es prevenir los delitos antes que castigarlos", aconsejó la creación de hospitales específicos para que las prostitutas infectadas pudieran recobrar la salud. La regulación de la enseñanza y práctica de la medicina, así como de otras profesiones relacionadas con el quehacer curador, ocupó un 
lugar destacado en las reflexiones de aquellos autores que se interesaron por la policía médica. Foronda dedicó algunas páginas a esta cuestión, proponiendo, básicamente, medidas encaminadas a asegurar la competencia de los profesionales sanitarios. Las parteras fueron el principal blanco de sus críticas pues consideró que por causa de su ignorancia se producían numerosos decesos al año, lo que le llevó a proponer que la obstetricia fuera exclusivamente practicada por cirujanos titulados.

Foronda abordó otros muchos temas relacionados con la salud pública en varias de sus cartas. En la IV, por ejemplo, escrita en 1800 y titulada Sobre calles, paseos, cafés, etc., formuló diversas recomendaciones para mejorar las condiciones higiénicas de las ciudades. Estableció que las calles debían ser rectas con el fin de asegurar una buena circulación del aire, y que tenían que pavimentarse con un empedrado fuerte y poseer suficiente inclinación para evitar los encharcamientos de agua. Cada acera debía tener una anchura de al menos seis pies para que los peatones no se vieran expuestos al riesgo de ser atropellados. Asimismo, el autor propuso que cada vecino tuviese la obligación de limpiar semanalmente la parte de la calle que quedaba frente a su domicilio. También aconsejó que los oficios molestos y contaminantes fueran desplazados a los arrabales de las ciudades, y recomendó que se velara por la limpieza de establecimientos públicos como fondas, botillerías y casas de juego.

Los autores hispanoamericanos que cultivaron la policía médica pusieron el acento en estos mismos temas. Un buen ejemplo de ello son las Reflexiones acerca de las viruelas escritas en 1785 por Francisco Javier Eugenio de Santa Cruz y Espejo, médico y prócer de la independencia de Ecuador. El autor abordó muchos de los asuntos que eran habituales en la literatura médico-policial europea, aplicándolos a la ciudad de Quito, y formuló numerosas recomendaciones para mejorar las condiciones higiénico-sanitarias de la localidad. Por ejemplo, consideró que el aire quiteño era "fétido y lleno de cuerpos extraños podridos", fenómeno que relacionó con la presencia de cerdos en la ciudad, el hábito de defecar en la vía pública, la costumbre de arrojar los desechos domésticos a las calles y la escasez de agua que corría por ellas (Santa Cruz y Espejo, 1912: 408). En la misma línea, puede citarse la obra de Hipólito Unanue, catedrático de prima de medicina en la Universidad de San Marcos, que entre 1791 y 1794 publicó en el "Mercurio Peruano" una serie de artículos que luego dieron lugar al libro Observaciones sobre el clima de Lima y sus influencias en los seres organizados, en especial el hombre, publicado por primera vez en 1802. Aunque la obra constituye un intento de explicación de las enfermedades prevalentes en Lima a partir de los supuestos aeristas, el autor se interesó por las condiciones higiénicas de la ciudad e instó a sus autoridades a que velaran por la limpieza y la salubridad del espacio urbano, señalando, entre otras cosas, que "las aguas que riegan las calles piden celo en el magistrado que cuida de ellas porque las balsas y lodazales que forman no solo dañan la salud del ciudadano inficionándole las aguas que bebe, sino también el aire que respira" (Unanue, 1806: x).

\section{La aplicación de los principios teóricos. El caso español}

\section{Regulación e intervencionismo estatal. La Junta Suprema de Sanidad}

Muchos de los asuntos que eran abordados de forma teórica por los tratadistas de la policía médica, fueron asimismo objeto de una minuciosa regulación legislativa por parte de los estados absolutistas europeos. El español fue uno de los más activos en este sentido ya que sancionó distintas leyes mediante las cuales pretendió crear las condiciones que permitiesen a los individuos mantener o aumentar su bienestar físico.

Aunque la mayoría de las disposiciones sanitario-preventivas se promulgaron en situaciones epidémicas de urgencia, adoptando, por ello, formatos normativos como el de las reales órdenes o las reales provisiones, la acción legislativa del poder central en materia sanitaria también pudo alcanzar un carácter más estructural. Prueba de ello son las Reglas y precauciones para evitar el uso de ropas y efectos de los éticos, tísicos y otros enfermos contagiosos, ley dictada el 6 de octubre de 1751, aplicable en el conjunto de los territorios de la Monarquía Hispana, que reguló 
diversas medidas para impedir la propagación de ese tipo de dolencias (Nov. Rec., lib. vii, tít. $x \mathrm{l}$, ley ii). En su primer punto, la norma decretó la obligación del personal sanitario de dar cuenta a las autoridades locales de cualquier incidencia clínica que acarrease un riesgo de contagio. En caso de que el enfermo falleciere, los dirigentes municipales debían asegurar "la total separación de la ropa, vestidos, muebles y demás cosas que le hayan servido personalmente, o hubieren permanecido en su cuarto o alcoba, para que inmediatamente se quemen, sin excepción alguna". Para el caso concreto de la Corte, la ley llegó a especificar el lugar en que debía realizarse la quema de las pertenencias del difunto -"en los sitios hondos del soto de Luzón o del de Perales, a media legua de distancia de Madrid"-, y a encarecer a los trabajadores del Hospital General de la villa a que "procedan con sumo cuidado en la práctica de las precauciones que quedan establecidas". Asimismo, las autoridades tenían que ordenar que el suelo de la habitación del fallecido fuera enladrillado de nuevo, y que las paredes fueran picadas, revocadas y blanqueadas. Para evitar la comercialización de las posesiones del difunto, la norma estableció diversos mecanismos de control de las mercaderías que se vendían en las almonedas, siendo especialmente rigurosa con "los prenderos, roperos de viejo y chalanes, porque son los que ordinariamente hacen negocio de semejantes efectos contagiosos".

Esta ley se complementó con unas Nuevas reglas que han de observarse para evitar el contagio de los éticos y tísicos, aprobadas el 23 de junio de 1752, cuya principal novedad radica en la integración del Real Tribunal del Protomedicato en el sistema de control sanitario (Nov. Rec., lib. vii, tít. xl, ley iii). Según la nueva normativa, los médicos que tuviesen noticia de la existencia de un enfermo contagioso ya no tenían que comunicárselo a las autoridades municipales, sino a ese Real Tribunal, el cual nombraría a un examinador para que visitase al afectado e informase sobre el carácter contagioso de la dolencia. En caso de discrepancia entre los dictámenes del primer médico y del examinador, el Protomedicato debería comisionar "más examinadores y cuantos médicos juzgare conveniente para que, conferida entre ellos la duda, resuelva el Tribunal lo que le parezca más probable y seguro".

Otra importante referencia legislativa son las Reglas sobre la policía de la salud pública que se han de observar por la Suprema Junta de Gobierno de Medicina, promulgadas el 15 de noviembre de 1796 (Nov. Rec., lib. vii, tít. $x l$, ley v). Los siete artículos de que consta dicha normativa regulan otros tantos aspectos que revelan los problemas sanitarios que mayor preocupación generaban entre las autoridades políticas de la época: 1) pureza del aire; 2) cementerios y forma de enterrar a los muertos; 3) ubicación de las fábricas y manufacturas insalubres; 4) localización y condiciones de los edificios públicos; 5) práctica de la inoculación contra la viruela; 6) vigilancia de la calidad de las bebidas y alimentos; y 7) control de los establecimientos dedicados a su venta y almacenamiento.

El poder central español intervino en otros muchos asuntos de interés sanitario a través de la Junta Suprema de Sanidad, cuya actividad merece ser examinada con un poco de detalle. Este organismo fue creado en 1720 para coordinar la defensa de España frente a la epidemia de peste que ese mismo año se desató en Marsella, pero una vez superado el riesgo de infección no se disolvió, sino que hasta 1847 continuó siendo el órgano de referencia de la administración sanitaria española. Pese a todas las críticas que puedan realizarse a la actuación de la Junta Suprema, es innegable que su persistencia tras el vendaval pestífero evidencia la voluntad de implantar una política sanitaria permanente y centralizada, cuyo cometido esencial será establecer los marcos normativos de referencia aplicables en el conjunto del territorio español. Más concretamente, la Junta Suprema de Sanidad constituyó la rama especializada del Consejo de Castilla para el ejercicio de funciones ejecutivas y directivas en el terreno sanitario (Varela Peris, 1998: 326). Bien es cierto que dichas funciones quedaron básicamente restringidas al plano administrativo, y aun esto último referido, casi con exclusividad, a la prevención de las enfermedades epidémicas, fundamentalmente la peste y la fiebre amarilla. Mas no puede soslayarse que en el siglo XVIII el concepto de sanidad tenía un sentido mucho más restrictivo que el actual, designando "la seguridad de no estar 
tocado de contagio, estando o viniendo de los lugares donde se padece" (Diccionario de la lengua castellana compuesto por la Real Academia Española, reducido á un tomo para su más fácil uso, 1780: 823).

Prácticamente todas las órdenes, instrucciones y recomendaciones emanadas de la Junta Suprema a lo largo del setecientos tuvieron como finalidad evitar la entrada o la propagación de enfermedades de gran incidencia social. La Junta fue la instancia que centralizó y canalizó la información concerniente a las epidemias extranjeras, y de ella partían las normas de interdicción que debían observarse, sobre todo, en los principales puertos de mar. La institución llevó a cabo dicha misión con solvencia y responsabilidad, pues a tenor de lo dispuesto por Pedro Felipe Monlau en su compendio de legislación sanitaria española, el periodo 1720-1800 "se distingue por el rigor de las medidas sanitarias, así como por la puntualidad y la fe con que los empleados y los pueblos se prestaban a cumplimentarlas" (Monlau, 1862: 1.255). Este mismo autor afirmó haber consultado en el archivo de la Junta Suprema una relación de las cuarenta y una epidemias -la mayoría de ellas de peste- que se declararon en Europa y el Mediterráneo entre 1720 y 1785 . Para prevenir estos morbos, la Junta Suprema decretó en varias ocasiones la incomunicación con los puertos sospechosos de albergar la infección o de no guardarse convenientemente de ella, medida que solía acompañarse de otras muchas disposiciones adicionales. Por ejemplo, con motivo de la peste de Argel de 1740 la Junta Suprema dictó unas Reglas que están mandadas observar para el resguardo de la salud pública en todos los puertos de estos reinos, en virtud de las cuales prohibió la admisión en los mismos de las embarcaciones procedentes de Argel, Esmirna y las islas del Egeo, y ordenó guardar cuarentena a las naves provenientes de Tabarca, Gibraltar y Mahón (Rodríguez Ocaña, 1987-88: 153).

Además de ocuparse de la sanidad marítima, la Junta Suprema intervino en distintos asuntos relativos a la salud interior. Es posible que los procedimientos puestos en práctica durante el decenio de 1720 en el sur de Cataluña, donde se desataron distintos brotes epidémicos, sobre todo de fiebres tercianas y tifoideas, contribuyeran decisivamente a for- jar un modelo de actuación político-administrativa para combatir las epidemias interiores, el cual se iría perfeccionando a lo largo del resto de la centuria. Manuel Arranz (1985) ha estudiado la conducta de las autoridades centrales y sus representantes regionales durante varias epidemias que se produjeron entre 1720 y 1730 en diversas localidades del Camp de Tarragona, mostrando la predisposición de esos políticos a auxiliar a los afectados, especialmente cuando la enfermedad se revelaba altamente contagiosa. Por ejemplo, ante la persistencia del paludismo en la Conca de Barberà, la Audiencia de Cataluña dispuso en 1727 que uno de sus miembros, el juez Gabriel de Rojas, se trasladara a dicho territorio para erradicar el mal e impedir que reapareciera. Rojas decidió crear tres nuevos hospitales -en Montblanc, I'Espluga de Francolí y Sarral- dedicados, exclusivamente, al tratamiento de los afectados por la epidemia. En cuanto a los aspectos preventivos, el juez estipuló que se completara el avenamiento de los terrenos pantanosos existentes en las cercanías de Montblanc, atendiendo a la común opinión de los médicos de que los pozos y aljibes de esta localidad se encontraban contaminados por miasmas provenientes de esos marjales. Asimismo, acordó que se llevaran a cabo obras de conducción de aguas desde alguna de las fuentes localizadas en los cerros de los alrededores de la villa.

Pese a que la principal misión de la Junta Suprema fue la prevención de las enfermedades contagiosas, este organismo intervino en otros muchos asuntos de interés sanitario, como revelan numerosos documentos custodiados en los fondos de sanidad del Archivo Histórico de la Ciudad de Barcelona (AHCB). En 1783 la Junta se interesó por la situación higiénica de las reales cárceles y hospicios de la ciudad, y exigió a sus autoridades que mejorasen las condiciones de limpieza y ventilación de estos establecimientos (AHCB, 1L.I-15B: 138). La institución también se ocupó de cuestiones vinculadas con el control de los alimentos, aunque casi siempre en relación a la entrada de productos extranjeros por vía marítima. Por ejemplo, en 1780 ordenó a las autoridades locales de Barcelona que no admitieran harinas y bizcochos procedentes de Lisboa, por haber causado la muerte de algunos consumidores (AHCB, 1L.I-14: 147), y en 1790 volvió a decretar medidas 
parecidas (AHCB, 1L.I-19: 46). Asimismo, el poder central fijó los aranceles, dietas y salarios que debía percibir el personal sanitario (AHCB, 1L.I-13: 40/3), e intervino, movido por un afán centralizador, en el nombramiento de diversos cargos de responsabilidad. Por ejemplo, en 1756 nombró a Carlos Segura como guardián del puerto de Barcelona, y su antecesor en el cargo, el barón de Guía Real, fue promovido a teniente de sanidad (AHCB, 1L.I-9: s/n).

La Junta Suprema también llevó su influencia a los ámbitos de la censura de libros médicos y de la enseñanza de la medicina. Hacia 1770 solicitó a la Academia Médica Matritense un informe acerca de los criterios que debían prevalecer a la hora de conceder las prescriptivas licencias de publicación, y por la misma fecha requirió al Protomedicato un dictamen sobre el plan presentado por la Universidad de Salamanca para la reforma de los estudios de medicina (Varela Peris, 1998: 329-330). Asimismo, la institución sanitaria procuró fomentar el conocimiento científico relativo a la prevención de las enfermedades. Así, Juan Díaz Salgado escribió por "encargo de la sanidad" un Sistema físicomédico-político de la peste (1756), obra que sería reeditada por orden del Real Consejo en 1787 y 1800. La Junta Suprema también hizo traducir y distribuir a sus homólogas periféricas algunas obras médicas extranjeras, como la "Disertacion medicohistórica sobre la elefancia" (1786), escrita en 1767 por el francés François Raymond.

Aunque la Junta Suprema constituyó el órgano de referencia de la sanidad española hasta bien entrado el siglo XIX, debemos reconocer, siguiendo a Esteban Rodríguez Ocaña (1987-88: 148-149), que nunca llegó a abarcar la pluralidad de funciones propuesta por los tratadistas de la policía médica. Ello dio ocasión a que se formularan algunas críticas a su modelo de funcionamiento. Por ejemplo, en 1792 el conde de Cabarrús dirigió una carta a Jovellanos en la que reprochó a ese organismo que "solo se aviva cuando oye hablar de peste", y en la que abogó por implantar una política sanitaria centralizada dedicada a combatir de forma permanente las dolencias de mayor incidencia social (Cabarrús, 1808: 62). Aunque las críticas de Cabarrús se antojan algo exageradas, pues la Junta
Suprema programó varias actuaciones para combatir algunas enfermedades endémicas, es innegable que el grueso de su actividad se focalizó en la lucha antiepidémica, especialmente en la vigilancia de la sanidad marítima. En cambio, las distintas juntas locales que se establecieron en los territorios periféricos del reino sí que impulsaron una acción sanitaria más extensa y ambiciosa. En cierto modo, su modelo de actuación se acercó al propuesto por Johann Heinrich Gottlob von Justi en su tratado de policía, no solo porque en ellas el papel de los médicos fue mucho más preponderante, sino también porque llevaron su esfera de intervención a una gran diversidad de frentes.

\section{La intervención de las autoridades} locales. Una aproximación a partir de las actividades de la Junta de Sanidad de Barcelona

Paralelamente a la actuación del Estado, durante el siglo XVIII diversas ciudades se dotaron de ordenanzas municipales que, entre otras muchas cosas, regularon aspectos relativos a la salud pública y la higiene urbana. Una referencia importante para la elaboración de estas ordenanzas fue el libro de Teodoro Ardemans Declaración y extensión sobre las Ordenanzas que escribió Juan de Torija (1719), que llegó incluso a ser utilizado por las autoridades municipales de Madrid para suplir la falta de legislación policial. En este trabajo el autor se interesó por algunos de los principales problemas higiénicos que afectaban a las ciudades, haciendo especial hincapié en la evacuación de las aguas. El tratamiento de estos temas por parte de los poderes locales puede ejemplificarse con las ordenanzas aprobadas en 1775 en la villa de Lopera, que han sido transcritas por Manuel Medina Casado (1996). Entre los preceptos más directamente relacionados con la sanidad podemos destacar la obligación de hacer pastar al ganado aquejado por alguna enfermedad contagiosa en lugares expresamente señalados (art. 29); la prohibición de que los cerdos beban de las fuentes públicas de agua potable (art. 33) y de lavar la ropa en estas mismas fuentes (art. 35); o el compromiso público de supervisar la calidad de la carne que se comercializa en la localidad (art. 39). 
Además de la elaboración de ordenanzas, los gobiernos municipales emprendieron numerosas iniciativas para tratar de mejorar las condiciones higiénico-sanitarias de sus respectivas ciudades. El de Madrid tuvo que ser uno de los más activos debido al deplorable saneamiento de la villa, causado, sobre todo, por la costumbre secular de arrojar las inmundicias a la vía pública desde las ventanas y balcones de las casas. La necesidad de introducir mejoras en la salubridad urbana dio lugar durante los años centrales del siglo XVIII a la realización de varios proyectos higiénicos, que han sido estudiados por Beatriz Blasco Esquivias (1998, 2002). Sin ánimo de exhaustividad, podemos mencionar los proyectos de Antonio de Ulloa, Jaime Bort y Pedro del Campo, que, en esencia, propusieron la instalación de cañerías y pozos negros para facilitar la evacuación y descarga de las aguas residuales y desechos orgánicos. Estas y otras propuestas cayeron en el olvido hasta el reinado de Carlos III, acaecido entre 1759 y 1788 , quien, a instancias de Francisco Sabatini, arquitecto de origen italiano que desarrolló la mayor parte de su carrera al servicio de la Monarquía Hispana, aprobó la Instrucción para el nuevo empedrado y limpieza de las calles de Madrid (1761), que permitió remediar muchas de las deficiencias higiénicas de la ciudad.

La traída de aguas a la villa fue otro asunto estrechamente relacionado con la higiene pública al que las autoridades madrileñas brindaron una gran atención. El crecimiento demográfico y las nuevas necesidades higiénicas obligaron a buscar fuentes alternativas de abastecimiento, lo que se tradujo en la elaboración de distintos proyectos de ingeniería hidráulica, siendo de destacar la ambiciosa propuesta presentada en 1768 por el ingeniero militar Jorge de Sicre y Béjar para trasvasar aguas del Jarama (Arroyo Ilera, 2004). Idéntica preocupación mostraron las autoridades locales de Cataluña, que en el transcurso del siglo XVIII, especialmente en su segunda mitad, acometieron numerosas obras de conducción y saneamiento de las aguas. Como ejemplo se puede aludir a la actuación de Antonio Quer y Villaró, titular de la vara de Balaguer, que dedicó buena parte del tiempo que permaneció en el cargo a mejorar la infraestructura hídrica de la ciudad (Irles, 1999: 150-151). El principal proyecto
Ilevado a cabo por este alcalde mayor consistió en la construcción de un nuevo tramo de la principal acequia que discurría por la localidad. Además, hizo reforzar las murallas para proteger la ciudad de las crecidas del Segre y ordenó cubrir un largo tramo de otra acequia con el fin de evitar accidentes.

Siendo la lucha antiepidémica la principal misión de la política sanitaria española del siglo XVIII, a nadie puede sorprender que la administración sanitaria en los territorios periféricos del reino difiriera en función de la ubicación de las distintas ciudades y regiones, haciéndose particularmente presente en los principales puertos marítimos. De este modo, fue configurándose una arquitectura institucional asimétrica cuyos orígenes se remontan, como en el caso de la Junta Suprema, a las disposiciones dictadas a principios de la década de 1720 para hacer frente a la peste de Marsella. En efecto, desde estas fechas ciudades portuarias como Barcelona, Valencia, Cádiz o Alicante contaron, dentro de sus respectivos organigramas de gobierno, con una delegación especial dedicada al quehacer sanitario. Las principales funciones de estas juntas locales de sanidad eran de índole administrativo-policial, pues debían hacer cumplir en sus respectivos ámbitos jurisdiccionales las disposiciones generales emanadas de la Junta Suprema para prevenir la introducción de los contagios extranjeros. Con todo, dichos organismos terminaron por rebasar este concreto ámbito del quehacer sanitario, extendiendo su radio de acción a otras parcelas, como la higiene pública o el control farmacéutico. El estudio de las actividades desarrolladas por la Junta de Sanidad de Barcelona nos permitirá arrojar alguna luz sobre ello.

La Junta de Sanidad de Barcelona fue el órgano delegado del Ayuntamiento de la ciudad, compuesto por seis regidores de dicha institución, que debía velar por la salud pública en la capital catalana. Como en el caso de las restantes juntas instituidas en los principales puertos marítimos de España, su principal función consistió en garantizar el estricto cumplimiento de las providencias dictadas por la Junta Suprema para prevenir la importación de los morbos extranjeros. Sin embargo, con el paso del tiempo su actividad tendió a ir rebasando este concreto desempe- 
ño, de forma que en las dos últimas décadas del siglo XVIII ya se nos presenta como un órgano plenamente consolidado, cuyos técnicos sanitarios intervienen en la mayoría de asuntos que afectan a la salud pública de la ciudad.

La mejor fuente para conocer la actuación llevada a cabo por esta junta son los fondos conservados en la sección de sanidad del Archivo Histórico de la Ciudad de Barcelona (AHCB). Dicha sección, una de las trece que conforman el Fondo Municipal, consta, a su vez, de doce series documentales, que suman un total de 271 unidades de instalación. La ingente cantidad de documentos custodiados hace posible un conocimiento integral de la situación sanitaria de Barcelona y de los procedimientos puestos en práctica para resguardar la salud de su población en los siglos XVIII y XIX. Nuestras indagaciones se han centrado en la primera de las series, titulada Registre d'edictes originals, reials decrets, ordres i oficis, que reúne todo tipo de disposiciones, ordenanzas y comunicaciones emitidas por las autoridades y el personal con competencias sanitarias. Está formada por 32 volúmenes, que abarcan los cien años comprendidos entre 1720 y 1820 . Nos hemos limitado a consultar los veintiún primeros tomos, pues en ellos se incluye la documentación expedida durante el siglo XVIII.

El estudio sistemático de esta documentación fue iniciado en 1982 por Iris Figuerola, quien ya puso de manifiesto la diversidad de competencias ejercidas por la Junta de Sanidad. Concretamente, esta autora clasificó el conjunto del material consultado en catorce apartados, que dan buena cuenta de dicha riqueza de funciones: 1) alimentos y su control; 2) animales (enfermedades y epizootias); 3) aranceles, dietas y salarios; 4) epidemias humanas (españolas y extranjeras); 5) farmacia; 6) gastos de sanidad; 7) inspección médica de embarcaciones; 8) lazareto de Barcelona; 9) lazareto de Menorca; 10) nombramiento de personal sanitario; 11) política sanitaria (epidemias y su control en Cataluña) e higiene pública; 12) rabia; 13) sanidad ambiental; y 14) tisis.

Como se ha avanzado, la principal competencia de la Junta de Sanidad de Barcelona fue la defensa de la ciudad frente a los mor- bos extranjeros. Siendo el puerto barcelonés uno de los principales del reino, este organismo constituyó un engranaje fundamental del sistema de resguardo sanitario organizado por la administración borbónica preliberal, debiendo velar por la estricta aplicación de las disposiciones emanadas de la Junta Suprema para prevenir las epidemias que se suscitaban en la cuenca mediterránea. En el ejercicio de esta función, la Junta tenía que impedir la entrada a través del puerto de Barcelona de las embarcaciones provenientes de lugares considerados como sospechosos, lo que planteó diversos enfrentamientos con los mercaderes y suscitó algunos conflictos de jurisdicción con los funcionarios de rentas (Martín Corrales, 1988). Los procedimientos profilácticos puestos en práctica cada vez que se declaraba el riesgo de infección no difirieron sustancialmente a lo largo de la centuria. Sin embargo, es innegable que estos mecanismos -que, básicamente, perseguían controlar y vigilar el tráfico marítimo comercial- se aplicaron con suma diligencia y rigurosidad, pues en el transcurso del siglo XVIII el Principado de Cataluña apenas se vio afectado por enfermedades epidémicas introducidas desde el exterior, lo que no había sucedido en épocas anteriores. Sin duda, el establecimiento de una burocracia jerárquica y centralizada, a través de la cual la información circulaba con relativa fluidez, contribuyó decisivamente al éxito del sistema de defensa sanitaria.

Como ejemplo de la actuación de la Junta de Sanidad en estos desempeños, podemos aludir al conjunto de providencias y comunicaciones dictadas a raíz de la peste de Argel de 1752 (AHCB, 1L.I-7). La Junta recibió la primera noticia de amenaza sanitaria el 7 de abril de este mismo año, cuando el marqués de la Mina, a la sazón capitán general de Cataluña, comunicó a la institución, por orden del Consejo de Castilla, la existencia en Argel de calenturas malignas que "parecían indicios y cuasi principio de morbo contagioso". El 10 de junio, Tomás de Miguel, gobernador de Ibiza, confirmó a la Junta el riesgo pestilencial, notificando, además, la llegada a la isla de varias embarcaciones mahonesas huidas de Argel, a las que se había concedido plática. Por esa fecha ya se habían comenzado a adoptar las primeras precauciones en el puerto de Barcelona, pues el 12 de junio se recibió una comunicación de los jurados y 
magistrados de Mahón -que, por aquel entonces, estaba en manos inglesas- en la que estos se quejaban por la aplicación de cuarentenas a las embarcaciones menorquinas, e informaban que en la isla no se estaba aceptando el desembarco de los navíos procedentes de Argel. Dos días después se recibieron nuevas noticias del Ayuntamiento de Palma, que hizo partícipe a la Junta barcelonesa de sus averiguaciones sobre la actividad mortífera de la peste en la ciudad norteafricana: "murieron el día uno de este mes cinco personas; el día dos, ocho; el día tres, dieciséis; el día cuatro no lo averiguó; y el cinco, veinticinco". El 20 de junio, el marqués de la Mina prohibió admitir a plática las embarcaciones desprovistas del correspondiente "depósito de sanidad", y ordenó aplicar cuarentena a las naves que procedieran de Gibraltar, Mahón y otros lugares sospechosos. Ese mismo día, el regidor municipal Luis Carbonell advirtió del peligro que representaba el no disponer de barcos de sanidad para evitar la entrada al puerto de las embarcaciones sospechosas, lo que fue resuelto con rapidez, pues el 22 de junio el marqués de la Mina dispuso que se sometiera a observación la nave propuesta por la Junta de Sanidad para la vigilancia del puerto, y dio orden a la Tesorería de abonar los cincuenta y dos reales diarios que se necesitaban para matricular el cabo y los seis marineros de dicho navío.

El 10 de julio, los jurados y magistrados de la sanidad de Mahón reiteraron a la Junta barcelonesa que en la isla se habían adoptado "estrictas medidas sanitarias" para prevenir el contagio, pero no hay constancia de que se suavizaran las precauciones aplicables a los buques menorquines. Mientras, la peste seguía causando estragos en Argel, pues el 11 de julio algunos patrones franceses notificaron a la Junta que "morían del contagio cincuenta personas cada día". Quizá por la gravedad de estas noticias, el 12 de julio el marqués de la Mina ordenó que no se admitiese el desembarco de una embarcación con esclavos redimidos de Argel, decisión que adoptó después de consultar a los "principales médicos de Barcelona". De hecho, el riesgo de contagio llegó a ser tal que las autoridades centrales se vieron obligadas a renovar el Edicto general de sanidad aprobado en 1740 con motivo de otra epidemia de peste declarada en la ciudad norteafricana, decisión que el capitán general comunicó a la Junta de Sanidad de Barcelona el 4 de septiembre. Dicho edicto prohibía en todos los puertos del reino la admisión de los navíos procedentes de Argel, Esmirna y las islas del Egeo, y decretaba la cuarentena para las embarcaciones originarias de Tabarca, Gibraltar y Mahón, así como para los navíos propios que hubiesen mantenido algún tipo de contacto con barcos provenientes de estos puertos. A partir de este momento, el sistema español de defensa frente a la peste de Argel quedó bien perfilado y la Junta de Sanidad continuó aplicando las prevenciones dictadas por la Suprema hasta el cese de la amenaza pestilencial. En una fecha tan tardía como el 23 de abril de 1753 el marqués de la Mina tuvo que ordenar a la Junta que continuara adoptando las providencias necesarias para prevenir el contagio, y a principios de 1756 el barco de sanidad del puerto de Barcelona todavía permanecía en funcionamiento, según consta en un escrito de 20 de enero dirigido al capitán general.

Además de asegurar el cumplimiento de todas las precauciones necesarias para prevenir las epidemias extranjeras, la Junta de Sanidad de Barcelona tuvo que intervenir con ocasión de numerosos contagios declarados en el interior de Cataluña, cumpliendo, de este modo, una inestimable función asesora. Por ejemplo, en 1781 los médicos de la institución -los doctores Rafael Steva, Pablo Balmas y Luis Prats- tuvieron que realizar dos dictámenes sobre una epidemia de fiebres pútridas suscitada en la lejana localidad de Agramunt, basándose en sendos informes remitidos por los médicos municipales de esta villa y por Joseph Vidal, catedrático de la Universidad de Cervera. En opinión de los facultativos barceloneses, la terapéutica prescrita por los médicos municipales resultaba poco efectiva, pues demoraba en demasía el uso de los purgantes (AHCB, 1L.I-14: 204). En cambio, coincidieron con el catedrático de Cervera en que era preciso extremar la higiene de las calles e internar en el hospital a cuantos no pudieran ser adecuadamente asistidos en sus propios domicilios (AHCB, 1L.I-14: 224). En el mismo año de 1781 llegaron noticias de que en la cercana población de Sant Andreu de la Barca algunas personas habían enfermado de tercianas, lo que motivó que el escribano de cámara de la Real 
Audiencia ordenara a los médicos de sanidad que se trasladaran a la población para que, "enterándose de las circunstancias de las enfermedades, sus progresos y métodos que se han de observar en su curación", emitieran el correspondiente dictamen (AHCB, 1L.I-14: 251/1), cosa que hicieron con gran celeridad, pues al cabo de dos días tuvieron concluido un informe en el que recomendaron el uso de la quina para combatir la enfermedad e indicaron la conveniencia de desaguar unos terrenos encharcados próximos al río Llobregat (AHCB, 1L.I-14: 253/1).

La vigilancia epidémica llevada a cabo por la Junta de Sanidad de Barcelona también incluía el control de las epizootias. Como ejemplo de su actuación en este particular puede aludirse al escrito remitido por los médicos de la institución el 16 de mayo de 1780 , relativo a una epizootia desatada en la región de Hamburgo y extendida al cabo de Istria y algunas provincias de Austria (AHCB, 1L.I-14: 151). En el informe que redactaron, los médicos Steva, Balmas y Prats establecieron las medidas que habían de ser adoptadas para prevenir el contagio, señalando que era preciso someter a cuarentena los cueros procedentes de la región afectada o de origen desconocido, así como prohibir la descarga de carnes y la venta de quesos y mantecas (AHCB, 1L.I-14: 181).

Lógicamente, los médicos de sanidad también se ocuparon de aquellas incidencias clínicas registradas en Barcelona que podían acarrear un riego de contagio. Así, por ejemplo, el 11 de mayo de 1773 estudiaron los informes que los facultativos Pedro Güell, Joaquín Rubira y Juan López habían realizado sobre el enfermo Antonio Zurita, opinando que éste había fallecido de hectiquez, y que, por tanto, "lo que ha usado desde que salió de Barcelona debe ser sujeto a la quema que disponen las reales ordenanzas" (citado en Figuerola y Esteva, 1979: 58).

La Junta de Sanidad de Barcelona también tenía a su cargo el cuidado del lazareto provisional de la ciudad, que se habilitaba cada vez que se declaraba la amenaza de infección. En 1775 los médicos del organismo visitaron el establecimiento, remitiendo un informe, fechado el 22 de mayo, en el que indicaron la necesidad de efectuar algunas reparaciones (AHCB, 1L.I-14: 19/2). Poco después, el 19 de julio, el barón de Serrahí, a la sazón secretario de cámara y de gobierno de la Audiencia de Cataluña, comunicó a la institución la entrega de 1.425 libras provenientes del fondo de la Real Hacienda para proceder a dichas reparaciones (AHCB, 1L.I14: 21). Los médicos de sanidad también opinaron sobre los procedimientos expurgatorios que se practicaban en el lazareto. En este sentido, puede citarse el informe que firmaron el 26 de octubre de 1772 relativo al sahumerio que la legislación recomendaba emplear para la limpieza de las embarcaciones, los géneros y las personas, pronunciándose en términos desfavorables, pues según habían podido comprobar "el antimonio, litargirio, azufre y pimienta que entran en dicho sahumerio pueden en efecto sofocar cualquier viviente, causarle apoplejías o efectos convulsivos por lo menos" (AHCB, 1L.I-13: s/n).

Los técnicos de la Junta participaron asimismo en las operaciones de control de la calidad de los alimentos que desembarcaban o se comercializaban en la ciudad, cuestión que suscitó una gran preocupación entre los médicos y políticos de la época, especialmente cuando se desataban brotes epidémicos en los centros habituales de provisión ganadera. En un estudio sobre la vigilancia alimentaria llevada a cabo en Barcelona entre 1720 y 1800 , se ha registrado una actividad especialmente intensa en el año 1783, fenómeno que se relaciona tanto con la aparición en diversos países europeos de enfermedades que alteraron el comercio ordinario de alimentos, como con la declaración en Cataluña de una epizootia que afectó al ganado porcino, bovino y caballar (Figuerola et al., 1986: 111). En estas circunstancias, los médicos de sanidad tuvieron que certificar el estado de algunos cargamentos de cacao, centeno, bacalao y arroz (AHCB, 1L.I-15: 1, 23, 154 y 164), y atendiendo a sus opiniones el barón de Serrahí autorizó su comercialización o, por el contrario, decretó su embargo. La esfera de intervención de la Junta también se extendió al control sanitario del comercio de ropas y enseres usados, capítulo de que fue objeto de numerosas ordenanzas y bandos en los que se advertía a la población, especialmente a los sectores más pobres, del riesgo que suponía la reutilización de prendas cuyo origen no estuviera certificado por los pre- 
ceptivos sellos de sanidad. Incluso el correo, al ser el papel considerado como un posible vehículo de transmisión de enfermedades, fue sometido a una estricta vigilancia sanitaria.

La Junta de Sanidad de Barcelona también solicitó la intervención de su equipo consultor de médicos para verificar la eficacia de algunas terapias y específicos farmacéuticos. Por ejemplo, el 7 de marzo de 1771 estos facultativos se pronunciaron favorablemente sobre una "máquina fumigatoria" destinada a reavivar personas aparentemente fallecidas, recomendando al Ayuntamiento la compra de varios de estos artilugios (AHCB, 1L.I-14: 106). Siguiendo este consejo, el consistorio adquirió dos máquinas, por lo que el 2 de julio los médicos de sanidad tuvieron que redactar una Instrucción para el uso de la máquina fumigatoria y de lo demás contenido en la caja para socorrer a los en apariencia muertos (AHCB, 1L.I-14: 111/2). En otra ocasión, los galenos de la sanidad municipal informaron negativamente sobre las propiedades de la espineta -planta que identificaron con el Echium, descrito ya por Dioscóridescomo específico contra la rabia, pues en su opinión el silencio de Boerhaave y de otros acreditados autores al respecto demostraba que la planta carecía de dicha cualidad medicinal (AHCB, 1L.I-14: 323).

Es, asimismo, interesante constatar cómo en diversas ocasiones la Junta de Sanidad de Barcelona tuvo que mediar entre el vecindario de la ciudad y la incipiente industria que comenzaba a implantarse en la misma. El contacto directo de los barceloneses con los pequeños talleres fabriles ubicados intramuros generó no pocos conflictos sanitarios que debieron ser dirimidos por la institución. Josep M. Calbet y Manuel M. Escudé (1996) han rescatado del Archivo Histórico varios de estos casos conflictivos, los cuales solían zanjarse con soluciones de compromiso, para, al mismo tiempo, resguardar la salud de la población y no poner trabas al incipiente desarrollo industrial de la ciudad. Por ejemplo, esos autores relatan el caso de una vecina de la calle Tallers que en 1774 denunció a la fundición contigua a su domicilio por los problemas de salud que le ocasionaba dicha actividad. Los doctores Steva y Balmas fueron comisionados para tratar el asunto, remitiendo un informe en el que confirmaron que la fundición generaba mucho calor y contaminaba el aire con partículas metálicas. Su recomendación fue que se construyera una pared medianera y una chimenea, solución que, al parecer, se llevó finalmente a la práctica.

El último capítulo que queremos destacar en relación a la actividad de la Junta de Sanidad de Barcelona es el que se refiere a la higiene pública y la salubridad del espacio urbano. Uno de los constantes motivos de preocupación de la institución fue la limpieza de las acequias que discurrían por el interior de la ciudad, especialmente del Rec Comtal, la principal de ellas, que, al acumular todo tipo de desechos y desperdicios, constituía un permanente y peligroso foco de infección. En septiembre de 1778 los médicos de la Junta recomendaron encarecidamente que se saneara la acequia, esgrimiendo que, como consecuencia del excesivo calor estival, los vapores exhalados podían resultar más perjudiciales de lo habitual, y agregando que en las inmediaciones de la ciudad ya se había detectado un incremento de la incidencia de las tercianas (AHCB, 1L.I-14: 87). La mejor forma de asegurar la limpieza de los cauces era proporcionándoles un caudal abundante, pues de este modo los desperdicios eran arrastrados con facilidad hasta ser vertidos al mar. Cuando ello no era posible fue necesario recurrir a los molinos de titularidad real, tal como se desprende de una comunicación del barón de Lalinde fechada el 2 de julio de 1782, mediante la cual este intendente general ordenó al administrador de esas instalaciones que adoptara las providencias necesarias para que no faltase agua en el $\operatorname{Rec}$ (AHCB, 1L.I-15A: 87).

Asimismo, la Junta de Sanidad se interesó por las condiciones higiénicas de las balsas de agua que se utilizaban para la maceración del cáñamo, dictando en una fecha tan temprana como 1722 una serie de normas para la limpieza de dichas pozas, y estableciendo los castigos que se aplicarían a los contraventores (AHCB, 1L.I-1: 51). Este asunto preocupó a la institución sanitaria durante todo el siglo XVIII, lo que da una idea de la importancia adquirida por esa actividad. Así, en 1785 los médicos de la Junta presentaron un informe sobre las condiciones que debía reunir el terreno para que se concediese el preceptivo permiso para empozar (AHCB, 1L.I-16B: 
13/2), y al año siguiente el alguacil mayor Francisco Alberch inspeccionó las balsas localizadas en varias localidades próximas a Barcelona, comunicando a la institución las infracciones observadas (AHCB, 1L.I-18: 105/2).

Además del saneamiento de las acequias y balsas para macerar, las autoridades sanitarias de Barcelona se preocuparon por la limpieza de la vía pública, que se solía extremar cuando alguna enfermedad amenazaba con propagarse epidémicamente por el interior de la ciudad. De este modo, el 4 de julio de 1783 el barón de Serrahí ordenó que se regaran diariamente las calles de la capital conforme a lo establecido por los médicos de sanidad, decisión que fue motivada por la existencia de un brote de calenturas pútridas (AHCB, 1L.I-15B: 89/1). Como la aparición de dicho brote se relacionó con las emanaciones provocadas por la limpieza de las letrinas, que, tradicionalmente, se practicaba en Cuaresma, el secretario de cámara y de gobierno de la Real Audiencia ordenó en noviembre de 1783 que esta operación solo pudiese ser llevada a cabo durante los meses fríos del año -diciembre, enero y febrero-y dentro de las horas comprendidas "desde que se abren las puertas de la ciudad hasta las nueve de la mañana" (AHCB, 1L.I-15B: 155). Unos años más tarde la misma autoridad dispuso que la limpieza de las letrinas se acometiese barrio a barrio, para que, de este modo, "quedasen libres las demás zonas del mal olor ocasionado (AHCB, 1L.I-17: 13).

Como es sabido, el pensamiento médico del siglo XVIII postuló que unas sustancias imperceptibles denominadas miasmas eran las responsables de la aparición y propagación de las afecciones epidémicas. Los miasmas eran elementos fétidos y malignos disueltos en la atmósfera y procedentes de las aguas estancadas, la materia orgánica putrefacta o los cuerpos enfermos o en estado de descomposición. Por este motivo, el destino de los cadáveres y de las pertenencias de los difuntos constituyó otro de los asuntos al que los médicos de la sanidad municipal tuvieron que prestar una atención creciente. Prueba de ello son los informes que estos facultativos presentaron el 4 y 6 de julio de 1776, en los que señalaron la conveniencia de que las "cajas de los muertos" fueran quemadas lejos de la ciudad $y$, de preferencia, en horario nocturno (AHCB, 1L.I-14: 47 y 49). Posteriormente, en un documento fechado el 10 de agosto de 1780, los médicos precisaron algunas indicaciones sobre lo que "deba hacerse en caso que el mar arroje algún cadáver, como también con la ropa de los difuntos de algún mal contagioso" (AHCB, 1L.I-14: 170). Sobre este último particular especificaron, por ejemplo, que no era necesario lavar las vestiduras del fallecido con cal, bastando "dos coladas buenas de lejía de ceniza".

La descomposición de los cadáveres de los animales constituía otro importante factor de riesgo sanitario ya que normalmente los cuerpos eran depositados en el Canyet, lugar de las afueras de la ciudad donde acostumbraban a ser pasto de los perros callejeros. El 14 de agosto de 1783, el Gremio de Curtidores de Barcelona se ofreció a enterrar debidamente los cadáveres si se les concedía la posibilidad de aprovechar sus pieles (AHCB, 1L.I-16A; 9/2), propuesta que fue sometida a la consideración de los médicos de sanidad. Estos remitieron un informe fechado el 20 de febrero de 1784 en el que desaconsejaron aceptar la propuesta ya que, en su opinión, los perros serían capaces de desenterrar los restos de los animales muertos, lo que "les dispone sin duda alguna a la rabia" (AHCB, 1L.I-16A: 9/1). En cambio, apuntaron la posibilidad de enterrar los animales en un sector de la playa convenientemente cercado.

Más allá de su carácter anecdótico, las incidencias que hemos ido relatando en las páginas precedentes revelan el tipo de prácticas que se generalizaron durante el siglo XVIII para garantizar la salud de la colectividad. La estrategia político-administrativa para la prevención de las enfermedades no solo se basó en la implantación de nuevas tecnologías de la salud, sino también en el despliegue, por parte de los médicos, de una intensa actividad científica encaminada a recabar informaciones relativas a las condiciones sanitarias y los peligros que acechaban a la sociedad. Es así como a lo largo de la centuria fueron apareciendo toda clase de informes médicos en los que se estudiaban, desde una perspectiva higiénico-sanitaria, áreas geográficas concretas y sus respectivas poblaciones, con el objetivo de proponer recomendaciones que permitiesen prevenir las enfermedades 
y fortalecer la salud de los habitantes. Fruto de este empeño es una voluminosa literatura médico-científica, que para el caso español ha sido parcialmente recogida por José $M$. López Piñero y sus colaboradores (López Piñero et al., 1992), de la que el informe que presentaremos a continuación constituye una excelente muestra.

\section{Las ideas médicas. El "Dictamen" de la Academia Médico-Práctica de Barcelona}

En mayo de 1780, la Junta de Sanidad de Barcelona solicitó a varios facultativos que esclarecieran las causas que podían estar originando un supuesto aumento en la incidencia de las apoplejías y muertes repentinas. El 31 de octubre de ese mismo año los doctores Steva, Balmas y Prats, que, como ya sabemos, formaban parte del equipo consultor de la Junta, respondieron a la solicitud de la misma con un informe de doce folios (AHCB. 1L.I14: 181). Por su parte, la Academia MédicoPráctica de Barcelona, institución creada en 1770, redactó un documento mucho más extenso -cuarenta y cinco folios de apretada letra- que no tuvo concluido hasta el 11 de junio de 1781 (AHCB. 1L.I-14: 207). Los académicos consideraron que el contenido de dicho manuscrito podía ser de utilidad para mejorar las condiciones sanitarias de otras ciudades españolas, lo que les animó a reescribir el informe y darlo públicamente a conocer en 1784, fecha en que la barceIonesa Imprenta de Carlos Gibert y Tutó lo publicó con el ampuloso título de Dictamen de la Academia Médico-Práctica de la Ciudad de Barcelona dado al mui llustre Aiuntamiento de la misma, sobre la frequencia de las muertes repentinas y apoplegias que en ella acontecen (en adelante "Dictamen").

En otro trabajo hemos presentado la estructura general de este documento, sus principales fuentes de inspiración y sus contenidos básicos, mostrando que el informe debe ser considerado, no tanto como una respuesta a la solicitud concreta efectuada por la Junta, sino como un panorama general de las condiciones sanitarias de Barcelona en la segunda mitad del siglo XVIII y de las posibilidades que brindaba el conocimiento médico-policial de la época para mejorar la higiene pública de las ciudades (Jori, 2009). En esta ocasión, queremos profundizar en el alcance de las propuestas formuladas por los académicos, mostrando su relación con las ideas científicas de la época acerca del origen y la evolución de las enfermedades.

Los académicos dedicaron gran parte del informe a analizar las causas que, de acuerdo con sus averiguaciones efectuadas en el año precedente, explicarían el deterioro de las condiciones urbanas de mortalidad, estableciendo que "ya por si solas, ya reunidas y combinadas de diferentes modos, son el fecundo manantial de donde dimanan, no solo las muertes repentinas, sino otras muchas $y$ graves enfermedades y epidemias" (Dictamen, 1784: 22). Aunque abordaron un gran número de causas, estas pueden agruparse en dos categorías estrechamente relacionadas: las que se refieren a la pureza del aire y las que aluden a la calidad de los alimentos. La medicina del setecientos solía recurrir a estos dos aspectos para explicar la etiología de las enfermedades. Conviene recordar que la microbiología solo se desarrolló a partir de la década de 1880, y aun así los descubrimientos en este campo tardaron en ser aceptados por toda la comunidad científica. En estas circunstancias, los factores ambientales en sentido amplio brindaron el marco interpretativo general para explicar el proceso de enfermar.

Las causas asociadas a la pureza del aire atmosférico son las que suscitaron un mayor interés entre los académicos. Estos calificaron al aire que se respiraba en las urbes como "denso, pesado, falto de elasticidad y lleno de partículas fétidas, corrompidas, acres, corrosivas y venenosas", para, a continuación, indicar algunos de los efectos que ocasionaba dicha contaminación atmosférica en el organismo humano: "debilita, relaja y corroe las fibras, irrita los nervios, disminuye la transpiración, hace la respiración difícil y ansiosa, corrompe los alimentos, comunica por varios caminos a los humores sus malas calidades, y perturba las secreciones y excreciones" (Dictamen, 1784: 26). Esta estricta relación de causalidad entre la mala calidad del aire y el debilitamiento del cuerpo debe inscribirse en el conjunto de teorías que trataron de establecer la correspondencia entre las condiciones ambientales y los problemas patológicos. Vale la pena examinar con un poco de detalle en 
qué consistieron tales teorías, pues desde nuestro punto de vista condicionaron el contenido de las propuestas de la policía médica destinadas a mejorar la higiene pública de las ciudades.

Los esquemas de razonamiento ambientalista basados en la doctrina humoral constituyeron una de las facetas del pensamiento hipocrático al que los médicos del siglo XVIII brindaron una mayor atención. Recordemos, simplemente, que la medicina hipocrática desarrolló una teoría ambiental de base fisiológica según la cual determinados agentes del medio físico -en especial la temperatura y la humedad- podían alterar el equilibrio interno de los humores, siendo, por tanto, causas eficientes de la enfermedad y la muerte. De esta doctrina, que se encuentra ampliamente desarrollada en el tratado "Sobre los aires, las aguas y los lugares" (s. V a. de C.), se desprendían dos corolarios de gran importancia: primero, que las peculiaridades somáticas y psíquicas de los individuos dependen en buena medida del medio geográfico en el que viven; segundo, que las condiciones topográficas, climáticas y atmosféricas deben ser escrutadas con el fin de conocer y prevenir las enfermedades (Urteaga, 1997: 10). Este ideario, resucitado y reformulado por Thomas Sydenham en el siglo XVII, tuvo una influencia extraordinaria en el pensamiento médico de la llustración, dando origen a una corriente neohipocrática que mostró una gran preocupación por el estudio del entorno y su relación con los problemas patológicos.

De todos los elementos del medio físico cuya influencia fue objeto de teorización, el aire atmosférico fue el que recibió una atención más pormenorizada por parte de la medicina del siglo XVIII. Si las epidemias afectaban simultáneamente a cientos o miles de personas de toda edad, género y condición, en buena lógica la causa de los brotes debía buscarse en aquello que todos los individuos tuviesen en común. La respuesta a este problema era bastante obvia ya que lo que todas las personas compartían era el aire que respiraban. De ahí que las condiciones cambiantes de la atmósfera fueran consideradas como las responsables de la aparición de las enfermedades, sobre todo las de carácter epidémico (Urteaga, 1993). La primera gran síntesis de la doctrina aerista fue debida a
John Arbuthnot, que en una monografía titulada An essay concerning the effects of air on human bodies (1733) describió las propiedades del aire y trató de correlacionar las variables atmosféricas con diferentes dolencias. El mismo Arbuthnot reconoció que las observaciones disponibles sobre el tiempo y el clima eran todavía escasas y poco concluyentes, lo que le obligaba "a razonar a partir de las leyes de la mecánica y las propiedades y cualidades conocidas del aire" (Arbuthnot, 1751: 146). Numerosos médicos contribuyeron durante el siglo XVIII a llenar ese vacío de observaciones fidedignas, llevando a cabo un meritorio esfuerzo de recopilación de datos meteorológicos y climatológicos que se vio favorecido por los adelantos que se produjeron en las técnicas de registro y medida del tiempo atmosférico (Capel, 1998-99).

Aunque el ambientalismo de tradición hipocrática constituyó una de las orientaciones más sólidas de la medicina de la Ilustración, numerosos facultativos se percataron que, por sí solo, este enfoque no permitía dar cuenta de todos los fenómenos observados. Por ejemplo, las variaciones térmicas o higrométricas no siempre presentaban una clara correspondencia con la virulencia de los brotes epidémicos. Además, las mismas dolencias podían aparecer en los más diversos climas y extenderse por todo tipo de territorios. A la vista de esta clase de observaciones, las explicaciones que consideraban el marco espacial como el principal agente etiológico tuvieron que complementarse con la doctrina miasmática de la enfermedad, que, como indicamos anteriormente, postuló que la corrupción debida a ciertas sustancias, efluvios o emanaciones constituía la causa última de las epidemias.

El empleo de dicha doctrina no dejaba de plantear numerosos interrogantes. A diferencia de otros elementos del medio físico, los miasmas no podían ser identificados ni medidos, lo que llevó a varios médicos a dudar de su existencia. Además, las emanaciones miasmáticas no siempre permitían explicar las incertidumbres etiológicas que iban surgiendo a medida que se multiplicaban las observaciones epidemiológicas, incluso cuando las explicaciones basadas en esos agentes morbosos se combinaban con el efecto de ciertas perturbaciones atmosféricas. Pero a 
pesar de estos problemas, la teoría atmosférico-miasmática fue más influyente que cualquier otra doctrina médica del contagio hasta finales del ochocientos, cuando por fin pudo demostrarse la transmisión microbiana de la enfermedad. De hecho, tal como han subrayado varios autores, este paradigma científico tuvo, pese a todas sus limitaciones teóricas, un papel decisivo en el desarrollo de las propuestas del higienismo para el fomento de la salud pública y la mejora de las condiciones sanitarias, especialmente en los espacios urbanos (Urteaga, 1985-86: 421; Heaman, 1995: 20; Buj, 2000: s/p.).

La aceptación de la doctrina miasmática implicaba reconocer la existencia de una serie de núcleos focales de la enfermedad, a partir de los cuales se creía que se difundían los peligrosos agentes mortíferos. Como es fácil de imaginar, la mayoría de los autores situaron dichos focos en los habituales lugares de podredumbre, tales como cárceles, cloacas o cementerios. Por ejemplo, en los albores del siglo XIX el médico Antonio Cibat tildó a las ciudades populosas y sucias de "almacenes de géneros averiados y podridos", y habló de los "gases contrarios a la vida que se levantan de los estercoleros, cloacas, hospitales, cárceles, casas o establecimientos piadosos de reclusión mal cuidados, pantanos o parajes cubiertos de aguas cenagosas y podridas" (Cibat, 1805: 9). Como ilustran las palabras de este facultativo catalán, muy frecuentemente los miasmas se asociaron a las áreas pantanosas y a la atmósfera urbana. Lo primero motivó que se llevaran a cabo diversas iniciativas de desecación de tierras, vinculadas, sobre todo, a la prevención de las tercianas. Y lo segundo condujo al desarrollo de la medicina urbana de la que nos habla Michel Foucault, quien considera a este modelo médico-social surgido en Francia durante la segunda mitad del siglo XVIII como un perfeccionamiento del esquema medieval de la cuarentena dirigido a la consecución de tres grandes objetivos: en primer lugar, el estudio de los lugares de acumulación y amontonamiento de desechos susceptibles de provocar enfermedades, es decir, de los lugares de donde procedían los temidos miasmas (cementerios, mataderos, cloacas, etc.); en segundo lugar, el control de los procesos de circulación del aire y del agua, dos elementos capaces de transportar los efluvios miasmáti- cos (métodos de ventilación, abastecimiento, saneamiento, etc.); en tercer lugar, la organización y seriación de los elementos necesarios para la vida en comunidad (fuentes, desagües, lavaderos fluviales, etc.) (Foucault, 1999b: 371-380).

Tras esta digresión, volvamos al "Dictamen" de la Academia Médico-Práctica de Barcelona. Siguiendo las ideas científicas en boga sobre el origen y la evolución de las enfermedades, los autores del informe identificaron seis grandes focos de contaminación atmosférica en la ciudad de Barcelona: el abigarrado tejido urbano; la deficiente e insuficiente red de alcantarillas; el insalubre sistema de letrinas y pozos ciegos; las exhalaciones cadavéricas procedentes de los cementerios parroquiales; las emisiones asociadas a determinadas actividades manufactureras; y el hacinamiento en establecimientos como las cárceles o el Hospital de la Santa Cruz. Para cada uno de estos puntos los académicos realizaron una serie de propuestas de intervención en el medio físico y social de la ciudad, que por razones de espacio nos limitaremos a enunciar:

1. Mitigar los efectos perniciosos de la densificación del tejido urbano limitando la altura de las edificaciones, prohibiendo los saledizos, mejorando la ventilación de las casas e impidiendo la instalación de oficios contaminantes en las calles más angostas.

2. Incrementar el caudal de agua que circula por las cloacas con el objetivo de facilitar su limpieza e impedir la putrefacción de las inmundicias que se depositan en ellas. Se proponen dos medios para aumentar dicho caudal: el vertido a las cloacas del agua recogida y canalizada en los tejados de los edificios, y el desvío de una parte del aforo del Rec Comtal hacia las alcantarillas maestras.

3. Incrementar el número de pozos negros, mejorar su construcción y ubicar dichas instalaciones lo más lejos posible de las casas. Asimismo, se apunta la necesidad de instalar respiraderos en las letrinas y de prohibir el vertido de basuras a través de sus conductos. También se señala la necesidad de limitar la limpieza de las fosas sépticas a las horas nocturnas y los meses fríos. 
4. Erradicar los cementerios localizados en el interior de la ciudad y ampliar el único camposanto extramuros existente en aquel momento -el actual Cementerio del Poble Nou- para convertirlo en el cementerio general de Barcelona.

5. Desplazar al exterior del recinto urbano todos los oficios contaminantes: veterinarios, curtidores, latoneros, plateros, boticarios, etc.

6. Asegurar una renovación continua del aire en el interior de los edificios públicos mediante la instalación del ventilador inventado por Samuel Sutton, oficial de la Royal Navy.

Las últimas páginas del "Dictamen" están consagradas a los problemas sanitarios ocasionados por el consumo de alimentos en mal estado. Los académicos limitaron sus comentarios al pan y el vino, dos productos básicos en la dieta de la época. Respecto al primero llegaron a establecer que "el pan, el alimento más esencial para el hombre, es después del aire la causa más común de enfermedades epidémicas siempre que es de mala calidad, ya sea por estar mal trabajado o amasado con agua mala, ya por ser hecho de arena averiada, o ya por ser de trigo demasiado nuevo o sobrado añejo, o humedecido o recalentado, o lleno de gorgojo o mezclado con cizaña" (Dictamen, 1784: 97-98). Para precaver este tipo de adulteraciones, los autores del informe recomendaron a las autoridades municipales prohibir la entrada de harinas a la ciudad y someter a un escrupuloso análisis todo el trigo de molienda. El comercio de vino también era objeto de varios abusos perniciosos para la salud pública. De todos los aditivos que se empleaban para falsificar la calidad de los caldos, los académicos hicieron hincapié en el parrell, yeso en polvo que se esparcía sobre la uva antes de ser pisada o que se arrojaba directamente a la bebida con la finalidad de aumentar su coloración. Los autores del "Dictamen" juzgaron que esta práctica, muy difundida en Cataluña, resultaba sumamente nociva para la salud, pues entre otras dolencias ocasionaba indigestiones y obstrucciones capilares y venosas. Es por ello que recomendaron a las autoridades erradicarla dictando las pertinentes medidas de policía.

Las propuestas de los académicos ni mucho menos cayeron en saco roto ya que la
Junta de Sanidad de Barcelona remitió varios escritos a la Real Audiencia de Cataluña para informar a este organismo de los diversos puntos abordados en el informe y proponer la ejecución de algunas medidas planteadas en el mismo. Nos queda pendiente la tarea de recopilar, transcribir y analizar todas estas comunicaciones, así como la de examinar las respuestas que obtuvieron y comprobar si algunas de las propuestas fueron llevadas a la práctica en los años posteriores. Aquí bastará con presentar un único ejemplo.

El 24 de octubre de 1782, dos regidores municipales (Manuel de Antich y Francisco de Novell) y el secretario de la Junta de Sanidad (Joseph Ignacio Claramunt y Verde) dirigieron una misiva al barón de Serrahí en la que, siguiendo muy de cerca el informe de la Academia Médico-Práctica, expusieron al secretario de cámara y de gobierno de la Real Audiencia su preocupación por el deterioro de la calidad del aire barcelonés provocado por la proliferación de industrias. Según argumentaron, "débese proteger el comercio, se ha de fomentar la industria, pero no se ha de permitir que a pretexto de uno y otra se menoscabe la salud del pueblo con que se destruiría insensiblemente la población que es la mayor riqueza del Estado" (AHCB. 1L.I-14: 189). Para tratar de conciliar ambos objetivos los firmantes de la carta reiteraron algunas de las propuestas formuladas por los académicos, como la de obligar a los boticarios a que establezcan sus laboratorios en las azoteas de los edificios. Pero al mismo tiempo discreparon de algunas opiniones expresadas por los autores del "Dictamen", considerando, por ejemplo, que el mal olor generado por ciertas actividades manufactureras no era una razón suficiente para desterrarlas de la ciudad.

\section{A modo de conclusión: la geografía histórica y el estudio de la sanidad}

Existe una larga tradición de intercambios entre la historia y la geografía, disciplinas que llegaron incluso a formar un grupo aparte en el sistema kantiano de las ciencias, por estudiar fenómenos únicos que se dan en el tiempo o en el espacio. Lamentablemente, la colaboración entre una y otra ha tendido a disminuir en las últimas décadas, distancia- 
miento que en parte puede explicarse por la irrupción de la geografía neopositivista, que al desplazar el énfasis hacia las relaciones y distribuciones espaciales relegó a la historia a un papel marginal en la explicación geográfica, o al menos condujo a una actitud decididamente ahistórica. La autonomía epistemológica de la geografía respecto a la historia, o respecto a cualquier otra disciplina, está fuera de cualquier duda. Sin embargo, estamos convencidos que el conocimiento geográfico solo será capaz de contribuir a encarar los problemas del mundo contemporáneo y a plantear críticamente los retos del nuevo milenio si se relaciona de manera intensa con otras ciencias, en especial, con la historia, que es la ciencia social por excelencia (Capel, 2006).

Los geógrafos pueden llegar a la historia por distintas vías. Por ejemplo, a través de la historia ambiental, que tanto por su vocación de saber multidisciplinario, como por sus objetivos y prácticas, se encuentra tan estrechamente vinculada a la geografía que algún autor ha llegado a cuestionar si realmente existe alguna diferencia entre ambas disciplinas (Colten, 1998: iii). El camino de la geografía a la historia también puede recorrerse a través de la geografía histórica, un subcampo disciplinario que en 1932 Edmund W. Gilbert ya definió como la rama del saber geográfico dedicada a "reconstruir la geografía regional del pasado" (citado en Baker, 2003: 33). Siguiendo este mismo enfoque, numerosos geógrafos han defendido que la geografía histórica debe poner el acento en la reconstrucción de los paisajes transformados por el hombre, más que en el hombre como agente transformador del paisaje (Baker, 1979).

La perspectiva de Carl O. Sauer permite arrojar alguna luz sobre la preocupación que subyace bajo la definición de este campo de estudio. Como es sabido, el geógrafo estadounidense pretendió a lo largo de toda su carrera alejar las investigaciones geográficas de los postulados deterministas, lo que ya en 1925 le llevó a proponer que la geografía debía dedicarse a estudiar las formas del paisaje que tienen un origen cultural. En un conocido artículo aparecido en 1931, Sauer continuó profundizando en los mismos temas, estableciendo que la misión de la geografía cultural reside en estudiar las expresiones del aprovechamiento humano sobre la superficie terrestre, con el objetivo de comprender la diferenciación de la Tierra en áreas culturales. El objeto de estudio sigue siendo el paisaje cultural, que es el resultado de la interacción entre una comunidad humana y sus circunstancias naturales, y que, por tanto, siempre es un residuo del tiempo, lo que obliga al investigador a considerar los cambios operados a través del mismo y a reconstruir las áreas culturales del pasado. Desde este punto de vista, la geografía histórica se ocuparía de "la serie de cambios por los que han atravesado los paisajes culturales, e involucra por tanto la reconstrucción de paisajes culturales anteriores" (Sauer, 2006: s/p.).

Desde la década de 1990, la crítica a los planeamientos sauerianos se ha fundamentado en el hecho de que restringen el campo de interpretación de los fenómenos culturales a los resultados operados por el hombre a través del tiempo, sin mayor o ninguna consideración por el estudio de la superestructura social, que englobaría las ideas, motivaciones, percepciones y valores de los agentes humanos que han contribuido a modelar el paisaje (Rucinque y Velásquez, 2007: 137). De esta forma, Robin A. Butlin defendió en un libro de 1993 que la geografía histórica se ha de dedicar a la reconstrucción de los procesos que resulten clave para el entendimiento del dinamismo de las actividades humanas que se desarrollan en el espacio, lo que implica la consideración de aquellos cambios registrados en la utilización de los recursos, la morfología y las funciones de los asentamientos humanos, el conocimiento geográfico o el ejercicio del poder.

En una línea bastante parecida, Leonard Guelke ha criticado la despreocupación por parte de la geografía histórica clásica de los aspectos relacionados con la filosofía de la historia, lo que habría llevado a conceptualizar la historia como equivalente de la "historia natural", que el autor define como "la explicación empírica de la naturaleza (incluida la humanidad), entendida como espectáculo digno de ser categorizado, ordenado y descrito por el observador" (Guelke, 1997: 217 , n. 3). Guelke propone reestructurar la subdisciplina a partir de una nueva noción de historia, que vaya más allá de su mera conceptualización en términos de cambio tempo- 
ral, y que incluya la consideración de cómo las personas han visto el lugar que ocupan en el mundo y cómo se han relacionado con sus semejantes en el medio físico. Como nos aclara el autor, "el entendimiento de los valores humanos y de las relaciones de poder que estos implican proporciona las bases para instaurar una nueva geografía histórica, la cual estimularía a los geógrafos a considerar las actividades del hombre en la tierra como una manifestación del pensamiento humano" (Guelke, 1997: 225). En cierto modo, no se redefine el objeto de estudio tradicional de la geografía histórica, sino que se replantea la forma en que esta subdisciplina se relaciona con la historia.

En la medida de las posibilidades, nuestra investigación se adscribe a estos últimos planteamientos teóricos, pues no trata de reconstruir geografías o paisajes de otras épocas, sino de aprehender el pensamiento de determinados agentes históricos y mostrar de qué modo sus acciones incidieron en la configuración del entorno físico. Más concretamente, nuestro trabajo pretende mostrar la incidencia espacial de la organización de la política de la salud en el siglo XVIII. Según hemos argumentado, la actitud abiertamente favorable del pensamiento económico de la época hacia las poblaciones numerosas, basada en la creencia de raíz mercantilista de que cuanto más poblado sea un país mayor será la capacidad del Estado para obtener riquezas y poder, motivó que durante esa centuria la salud y la enfermedad comenzaran a ser conceptualizadas como problemas políticos y económicos que demandaban una gestión pública. En el plano teórico, los tratadistas de la policía médica formularon numerosas propuestas de intervención en el medio físico y social para elevar el nivel de salud de la población, y defendieron que la ejecución de tales medidas debía corresponder al poder político. Este, a su vez, fue irrogándose una misión de policía sanitaria que acabaría abarcando una gran pluralidad de frentes, tales como la vigilancia de la sanidad marítima, la regulación de la enseñanza y de la práctica profesional de la medicina o el control de las condiciones higiénico-sanitarias de las localidades.
Asimismo, hemos puesto de relieve que en el marco de la política de la salud del siglo XVIII, muy condicionada por el enfoque predominante en la literatura médicocientífica de la época, que recurría a los factores ambientales para explicar el origen y la evolución de los procesos patológicos, afloró una gran preocupación por la salubridad de los espacios urbanos, cuyas deficientes condiciones higiénicas ocasionaban graves perjuicios sanitarios y, por ende, económicos. Es así como la llustración persiguió instaurar un nuevo orden urbano basado en la higiene y la asepsia colectivas, lo que se tradujo en la concepción y ejecución de medidas de policía que tenían como finalidad combatir la degradación física y moral del ciudadano para hacer de él un individuo sano y disciplinado. Por esta vía se anticiparon, al menos esquemáticamente, algunos principios generales de la planificación urbanística que se institucionalizaría en la segunda mitad del siglo XIX. Como ejemplo, puede aludirse a la política de construcción de parques urbanos que se llevó a cabo durante este periodo en numerosas ciudades, pues dichos espacios fueron vistos como un modo de difundir una cultura "positiva" entre el proletariado industrial (Capel, 2002: 321-324). El arquitecto paisajista Frederick Law Olmsted, responsable del diseño del Central Park de Nueva York, fue uno de los más acérrimos defensores de la función higienizadora -a la vez física y moralde los parques. Así, entre los argumentos que consideró para la creación del parque Mont-Royal de Montreal figuran "las plenas necesidades de ejercicio y una ocupación mental alegre al aire libre [que obtendrán los ciudadanos], con el resultado de una mejor salud y buena forma en todo lo que respecta a las pruebas y los deberes de la vida" (citado en García Hermosilla, 1998: 372).

Seguiremos profundizando en estos temas con la firme convicción de que el entendimiento de los espacios y las sociedades actuales debe necesariamente derivar de la comprensión de los procesos que han sido operativos en el pasado. De ahí la necesidad de continuar enriqueciendo la geografía histórica con nuevas investigaciones que hagan hincapié en las representaciones sociales que, históricamente, han fundamentado el ejercicio del poder. 


\section{Referencias bibliográficas}

ARCHIVO HISTÓRICO DE LA CIUDAD DE BARCELONA (AHCB). Fondo Municipal (1), Sección de Sanidad (L), Serie "Registro de edictos originales, reales decretos, órdenes i oficios" (I).

ARBUTHNOT, J. An essay concerning the effects of air on human bodies. London: J. and R. Tonson and S. Draper, 1751 [1733].

ARDEMANS, T. Declaración y extensión sobre las Ordenanzas que escribió Juan de Torija. Madrid: Francisco del Hierro, 1719.

ARRANZ I HERRERO, M. Epidèmies i crisis agràries a la Catalunya Nova en els decennis de 1720: I'actitud de les autoritats borbòniques. Aplec de Treballs, 1985, № 7, p. 193-216.

ARROYO ILERA, F. Arbitrismo, población e higiene en el abastecimiento hídrico de Madrid en el siglo XVIII. Boletín de la Asociación de Geógrafos Españoles, 2004, № 37, p. 257-278.

BAKER, A. Historical geography: a new beginning. Progress in Human Geography, 1979, Vol. III, No 4, p. 560-570.

BAKER, A. H. Geography and history. Bridging the divide. Cambridge: Cambridge University Press, 2003.

BERGASSE, N. Lettre d'un médecin de la Faculté de Paris à un médecin du Collège de Londres. La Haye: s/e., 1781.

BLASCO ESQUIVIAS, B. ¡Agua va! La higiene urbana en Madrid (1561-1761). Madrid: Caja Madrid, 1998.

BLASCO ESQUIVIAS, B. Tradición y reforma en el Madrid de Fernando VI: la policía urbana y el progreso de la ciudad. En: BONET CORREA, A. (director). Un reinado bajo el signo de la paz. Fernando VI y Bárbara de Braganza. Madrid: Ministerio de Educación, Cultura y Deporte, 2002, p. 53-89.

BUJ, A. De los miasmas a malaria.www. Permanencias e innovación en la lucha contra el paludismo. Scripta Nova. Revista
Electrónica de Geografía y Ciencias Sociales, 2000, Vol. IV, No 69 (62). Disponible en Internet: http://www.ub.es/geocrit/sn-69-42.htm

BUTLIN, R. Historical geography. Through the gates of space and time. London: Edward Arnold, 1993.

CABARRÚS, F. Cartas sobre los obstáculos que la naturaleza, la opinión y las leyes oponen a la felicidad pública. Vitoria: Pedro Real D., 1808.

CALBET CAMARASA, J.M. y ESCUDÉ AIXELA, M. Conflictes sobre higiene pública a Barcelona a les darreries del segle XVIII. Cimbernat. Revista Catalana d'Història de la Medicina i de la Ciència, 1996, Vol. XXV, p. 43-51.

CAPEL, H. Medicina y clima en la España del siglo XVIII. Revista de Geografía, 199899, Vol. XXXII-XXXIII, p. 79-105.

CAPEL, H. La morfología de las ciudades. Vol. I: Sociedad, cultura y paisaje urbano. Barcelona: Serbal, 2002.

CAPEL, H. EI VIII Coloquio Internacional de Geocrítica. Una geografía histórica para construir el futuro. Scripta Nova. Revista Electrónica de Geografía y Ciencias Sociales, 2006, Vol. X, No 218 (001). Disponible en Internet: http://www.ub.es/geocrit/sn/sn-218001.htm

CIBAT, A. Memoria sobre la naturaleza del contagio de la fiebre amarilla, medios para precavernos de él y evitar que se haga endémico en nuestra España. Barcelona: Brusí y Ferrer, 1805.

COLTEN, C. Historical Geography and Environmental History. Geographical Review, 1998, Vol. LXXXVIII, No 2, p. iii-iv.

DELAMARE, N. Traité de la police. Tome premier. Paris: Jean et Pierre Cot, 1705.

DICCIONARIO de la lengua castellana compuesto por la Real Academia Española, reducido á un tomo para su más fácil uso. Madrid: D. Joaquín Iborra, 1780.

DICTAMEN de la Academia MédicoPráctica de la Ciudad de Barcelona dado al 
mui Ilustre Aiuntamiento de la misma, sobre la frequencia de las muertes repentinas y apoplegias que en ella acontecen. Barcelona: Carlos Gibert y Tutó, 1784.

DÍAZ SALGADO, J. Systema physico medico-politico de la peste, su preservacion y curación, para el uso y instruccion de las diputaciones de sanidad de este reyno. Madrid: Oficina de Antonio Sanz, 1756.

FIGUEROLA, I. Iniciación al estudio de la sanidad en Cataluña, 1720-1800. Barcelona: tesis doctoral, Universidad de Barcelona, 1982.

FIGUEROLA, I. y ESTEVA J. Rafael Steva, Pablo Balmas y Luis Prats y el control médico-farmacéutico en Barcelona (1771-1781). En: VV.AA. Jesús Isamat Vila. Primer profesor de historia de la farmacia en la Facultad de Farmacia de Barcelona. Barcelona: Universidad de Barcelona, 1979, p. 53-79.

FIGUEROLA, I.; ESTEVA J. \& ESPINOSA E. Els metges de sanitat de Barcelona i el control de la qualitat dels aliments (s. XVIII). Gimbernat. Revista Catalana d'Història de la Medicina i de la Ciència, 1986, Vol. VI, p. 107-114.

FORONDA, V. Cartas sobre la policía. Madrid: Imprenta de Cano, 1801.

FOUCAULT, M. Nacimiento de la biopolítica. En: Obras esenciales. Vol. III: Estética, ética y hermenéutica. Barcelona: Paidós, 1999 (a) [1979], p. 209-215.

FOUCAULT, M. Nacimiento de la medicina social. En: Obras esenciales. Vol. IV: Estrategias de poder. Barcelona: Paidós, 1999 (b) [1974], p. 363-384.

FOUCAULT, M. La política de la salud en el siglo XVIII. En: Obras esenciales. Vol. II: Estrategias de poder. Barcelona: Paidós, 1999 (c) [1976], p. 329-342.

FRAILE, P. Urbanismo y control social en los tratados de policía. En: LÓPEZ PIÑERO, J.; CAPEL, H. y PARDO TOMÁS, J. (coordinadores). Ciencia e ideología en la ciudad. Valencia: Generalitat Valenciana, 1991, Vol. I, p. 133-146.
FRAILE, P. La otra ciudad del Rey. Ciencia de policía y organización urbana en España. Madrid: Celeste, 1997.

FRAILE, P. Putting order into the cities: the evolution of 'policy science' in eighteenth-century Spain. Journal of Urban History, 1998, Vol. XXV, No 1, p. 22-35.

FRANK, Johann P. A system of complete medical police. Selections from Johann Peter Frank. Edited with an introdution by Erna Lesky. Baltimore: The John Hopkins University Press, 1976 [1779-1827].

GARCÍA HERMOSILLA, C. Los parques urbanos de Barcelona y Montréal durante el siglo XIX. En: CAPEL, H. y LINTEAU, P. (directores). Barcelona-Montréal. Desarrollo urbano comparado. Barcelona: Universidad de Barcelona, 1998, p. 371-376.

GUELKE, L. The relations between geography and history reconsidered. History and Theory, 1997, Vol. XXXVI, № 2, p. 216-234.

HEAMAN, E. The Rise and Fall of Anticontagionism in France. Canadian Bulletin of Medical History, Vol. XII, No 1, 1995, p. 3-25.

HOSELITZ, B. Los objetivos y la historia de las teorías del desarrollo económico. Revista de Economía Política, 1953, № 11, p. 9-28.

IRLES VICENTE, M. Proyectos y realidades: higiene y salud pública en la Cataluña de finales del Setecientos. Revista de Historia Moderna, 1999, No 17, p. 147-165.

JORI, G. Higiene y salud pública en Barcelona a finales del siglo XVIII. El Dictamen de la Academia Médico-Práctica de Barcelona (1784). Biblio 3W. Revista Bibliográfica de Geografía y Ciencias Sociales, 2009, Vol. XIV, No 832. Disponible en Internet: http://www.ub.es/geocrit/b3w-832.htm

JUSTI, J. Ciencia del Estado. Traducción de Antonio Francisco Puig y Gelabert (1784). Preparación y estudio introductorio de Omar Guerrero Orozco. Toluca: Instituto de Administración Pública del Estado de México, 1996 [1758]. 
LÓPEZ PIÑERO, J. et al. Bibliographia medica hispanica, 1475-1950. Vol. III. Libros y Folletos, 1701-1800. Valencia: Universidad de Valencia/CSIC, 1992.

MARTÍN CORRALES, E. El contrabando en el litoral catalán durante el reinado de Carlos III. Pedralbes. Revista d'Història Moderna, 1988, No 8 (1), p. 485-494.

MEDINA CASADO, M. Las ordenanzas municipales de Lopera de 1775. En: VV.AA. Actas del I Congreso 'La Ilustración y Jaén'. Jaén: Universidad de Jaén, 1996, s/p.

MITJAVILA Y FISONELL, V. Compendio de policia medica. Suplemento al Semestre Médico Clínico, 1803, p. 63-172.

MONLAU, P. Elementos de higiene pública o arte de conservar la salud de los pueblos. Vol. III: Legislación sanitaria. Madrid: Carlos Bailly-Bailliere, 1862 [1847].

Novísima Recopilación de las Leyes de España. Madrid: s/e., 1805, 5 Vol.

RAU, W. Gedanken von dem nutzen und der nothwendigkeit einer medicinischen policey-ordnung in einem Staat. UIm: Stettin, 1764.

RAYMOND, F. Disertación medicohistórica sobre la elefancia y su distinción de la lepra. Madrid: Imprenta de Pacheco, 1786.

RODRÍGUEZ OCAÑA, E. El resguardo de la salud. Organización sanitaria española en el siglo XVIII. Dynamis, 1987-88, Vol. VII-VIII, p. 145-170.

ROSEN, G. Cameralism and the Concept of Medical Police. Bulletin of the History of Medicine, 1953, Vol. XXVII, p. 21-42.

RUCINQUE, H. y VELÁSQUEZ A. Geografía e historia ¿Reactivación de antiguas relaciones interdisciplinarias? Revista de Relaciones Internacionales, Estrategia y Seguridad, 2007, Vol. II, No 2, p. 127-148.

SANTA CRUZ Y ESPEJO, F. Reflexiones acerca de las viruelas. En: Escritos del Doctor Francisco Javier Eugenio Santa Cruz y Espejo. Quito: Imprenta Municipal, 1912 [1785], Vol. II, p. 341-522.

SAUER, C. La geografía cultural. En: GÓMEZ MENDOZA, J.; En: GÓMEZ MENDOZA, J.; MUÑOZ JIMÉNEZ, J.; ORTEGA CANTERO, N. y ORTEGA, N. (compiladores). El Pensamiento geográfico. Estudio interpretativo y antología de textos. (De Humboldt a las tendencias radicales). Madrid: Alianza, 1982 [1931], p. 349-354.

SAUER, C. La morfología del paisaje. Polis, 2006 [1925], № 15. Disponible en Internet: http://www.revistapolis.cl/15/sau.htm

UNANUE, H. Observaciones sobre el clima de Lima y sus influencias en los seres organizados, en especial el hombre. Lima: Imprenta Real de los Huérfanos, 1806 [1802].

URTEAGA, L. Higienismo y ambientalismo en la medicina decimonónica. Dynamis, 1985-86, Vol. V-VI, p. 417-425.

URTEAGA, L. La teoría de los climas y los orígenes del ambientalismo. Geocrítica. Cuadernos Críticos de Geografía Humana, 1993, No 99 , p. 5-55.

URTEAGA, L. Ideas medioambientales en el siglo XVIII. Madrid: Akal, 1997.

VARELA PERIS, F. El papel de la Junta Suprema de Sanidad en la política sanitaria española del siglo XVIII. Dynamis, 1998, Vol. XVIII, p. 315-340. 